OPEN ACCESS

Edited by:

Diego Manzoni,

University of Pisa, Italy

Reviewed by:

Hans Straka,

Ludwig Maximilian University

of Munich, Germany

Manxiu Ma,

Fralin Biomedical Research Institute,

Virginia Tech Carilion, United States

${ }^{*}$ Correspondence:

Didier Le Ray

didier.leray@u-bordeaux.fr

${ }^{{ } \text {Present address: }}$

Mathias Guayasamin

Rejean Dubuc's lab, Université de

Montréal, Montreal, QC, Canada

Received: 03 December 2021

Accepted: 07 February 2022

Published: 03 March 2022

Citation:

Le Ray D and Guayasamin M (2022) How Does the Central Nervous System for Posture and Locomotion Cope With Damage-Induced Neural Asymmetry?

Front. Syst. Neurosci. 16:828532. doi: 10.3389/fnsys.2022.828532

\section{How Does the Central Nervous System for Posture and Locomotion Cope With Damage-Induced Neural Asymmetry?}

\author{
Didier Le Ray* and Mathias Guayasamin ${ }^{\dagger}$ \\ Université de Bordeaux, CNRS, EPHE, INCIA, UMR 5287, Bordeaux, France
}

In most vertebrates, posture and locomotion are achieved by a biomechanical apparatus whose effectors are symmetrically positioned around the main body axis. Logically, motor commands to these effectors are intrinsically adapted to such anatomical symmetry, and the underlying sensory-motor neural networks are correspondingly arranged during central nervous system (CNS) development. However, many developmental and/or life accidents may alter such neural organization and acutely generate asymmetries in motor operation that are often at least partially compensated for over time. First, we briefly present the basic sensory-motor organization of posturo-locomotor networks in vertebrates. Next, we review some aspects of neural plasticity that is implemented in response to unilateral central injury or asymmetrical sensory deprivation in order to substantially restore symmetry in the control of posturo-locomotor functions. Data are finally discussed in the context of CNS structure-function relationship.

Keywords: sensory-motor integration, neuronal networks, injury, motor recovery, development

\section{INTRODUCTION}

The development of pluricellular organisms depends primarily on the establishment of both radial and bilateral symmetries, which are considered to be determined genetically (Holló, 2015), even though symmetry breaks are necessary for certain physiological functions to be effective (Moubayidin and Østergaard, 2015). Nevertheless, body asymmetry is very common in invertebrates and ancestral vertebrates, whereas it is much less obvious in mammals even if they retain some of such characteristics (Andrew, 2009).

Asymmetries exist in the organization of all inner organs, including the central nervous system (CNS; Concha and Wilson, 2001; Blum and Ott, 2018; Schweickert et al., 2018). However, imaging approaches in human subjects indicated that no gross morphological nor functional asymmetry exist in the posturo-locomotor nervous system, from the cortex to the lumbar spinal cord (White et al., 1997), including cerebellar (Grodd et al., 2001) and cortical (Overduin and Servos, 2008) sensory-motor representation networks. Indeed, in vertebrates both locomotion and posture require bilateral symmetry in spinal sensory-motor circuits that mirrors the symmetrical organization of their biomechanical apparatus (Farel and McIlwain, 2000; Cooke, 2004). Such 
sensory-motor CNS symmetry, built during early development and refined during growth, has been shown to ensure symmetrical locomotion and effective postural adjustments in humans (Gervasio et al., 2015).

Much evidence from both human and animal studies indicates that the CNS is capable of considerable plasticity, both at the structural and functional levels. Such a plastic ability is evoked as soon as early development and is conserved into adulthood. The posturo-locomotor nervous system is also subject to significant plasticity in response to learning or accidental injury. For instance, although basically symmetrical, postural control in humans can be trained to become asymmetrical, expressed as a constant displacement of the center of pressure relative to the vertical body weight vector (Shiller et al., 2017), demonstrating the inherent ability of the symmetrically organized motor nervous system to generate a permanent asymmetrical command. Similarly, decerebrate cats walking on a laterally tilted treadmill are able to maintain body balance by transforming a naturally symmetrical locomotor pattern into an asymmetrical one (Musienko et al., 2014), and the enforcement of an asymmetrical gait to spinalized cats changes spinal sensory-motor processes to prevent additional disequilibrium (Hurteau and Frigon, 2018). In opposite, a sensory imbalance experimentally generated in the neck of squirrel monkeys induced a motor disequilibrium that was reversed within days (Igarashi et al., 1969). This latter suggests that in response to an imposed asymmetry (for instance, consecutive to central or sensory injury or disease) the posturolocomotor neural system has the capacity to adapt and to restore symmetrical motor functions.

Here, we will review some of the neural mechanisms involved in restoring functional symmetry in the control of posture and locomotion in vertebrates, with a particular emphasis on vestibular unilateral deprivation. We will start with a brief reminder of the general organization of the neural posturolocomotor system, followed by its structural and functional adaptations to imposed central or sensory asymmetry in both adults and subjects in development. We will particularly focus on research allowing to investigate the relationship between neural structure and behavioral function and how it is established during development.

\section{POSTURO-LOCOMOTOR NETWORKS IN VERTEBRATES}

\section{Spinal Networks}

The control of posture and locomotion requires the sequential and, at least in the case of locomotion, rhythmic activation of series of skeletal muscles bilaterally distributed along the body. Recruitment of these muscles during locomotion is primarily ensured by basic motor commands generated by the so-called central pattern generators (CPGs; Figure 1A; for recent reviews, see Côté et al., 2018; Grillner and Kozlov, 2021). Briefly, basic commands are organized by sets of excitatory interneurons (INs), which are arranged in modules generating fundamental recurring activity, and which are coordinated through inhibitions implicating a variety of local inhibitory INs
(Cangiano and Grillner, 2005; Grillner et al., 2005; Berkowitz et al., 2010; Bagnall and McLean, 2014; Jay and McLean, 2021). Bilateral coordination depends specifically on commissural INs while ipsilateral (e.g., flexor/extensor) coordination depends on ipsilateral INs. These interneuronal networks connect motor neurons (MNs) that transmit central motor commands to effector muscles. However, MNs are not just passive output neurons. As it is the case for INs in the CPG, MNs possess some particular membrane properties, such as the persistent sodium current ( $\mathrm{I}_{\mathrm{NaP}}$; Tazerart et al., 2007, 2008), allowing them to integrate rather than just follow the numerous synaptic inputs they receive. Locomotor CPGs are localized in the spinal cord, and their organization depends on the animal biomechanical apparatus.

In fish or larval amphibian, both propulsion and posture are ensured by axial muscles that are organized in myotomes distributed along the body axis (D'Elia and Dasen, 2018) and controlled by bilaterally alternating neuronal networks, segmentally iterated throughout the spinal cord (Roberts et al., 2010; Berg et al., 2018). In contrast, in quadrupeds the CPGs dedicated to fore- and hindlimb movements are respectively segregated in cervical and lumbar segments (e.g., in rats: Ballion et al., 2001, and Cazalets et al., 1995, respectively), coordinated through propriospinal pathways (Juvin et al., 2005, 2012), and are putatively organized in interconnected modules, each responsible for the command of flexion/extension cycles at a single joint (Grillner and El Manira, 2020; Grillner and Kozlov, 2021). However, the exact nature and organization of CPGs in mammals remain unclear, although the rise of genetic approaches has already allowed the identification of several populations of INs putatively involved in rhythm-generating GPGs (Goulding, 2009; Rancic and Gosgnach, 2021).

The postural nervous system, in contrast, is largely distributed along the spinal cord. Although variations exist between species and in accordance with the type of posturo-locomotor movements they produce, each spinal segment participates in organizing the axial muscle contractions responsible for postural activities (reviewed in Guillaud et al., 2020). Globally, postural control can be separated into two major functions: one is dedicated to body stabilization in the absence of goal-directed movement and resists external perturbations including gravity, while the other is dynamically engaged during self-motion and ensures body balance and orientation in space. Usually, the control of posture, whether it concerns perturbation-induced reflexes or gait-related control, is considered to depend mainly on descending commands from supraspinal centers (reviewed in Takakusaki, 2017), partly because the available knowledge about the organization and dynamic activity of spinal postural networks is scarce. In fact, most data come from analyses of thoracic back muscles during locomotion. In rats (Falgairolle and Cazalets, 2007) as in humans (de Sèze et al., 2008), metachronal propagations of back muscle contraction were observed to occur with comparable patterns during walking. Moreover, such metachronal waves were found to persist in thoracic ventral root recordings during pharmacologically induced fictive locomotion in the in vitro isolated spinal cord of newborn rats, suggesting the existence of a propriospinal coordination between the CPG for locomotion and the thoracic networks 
A

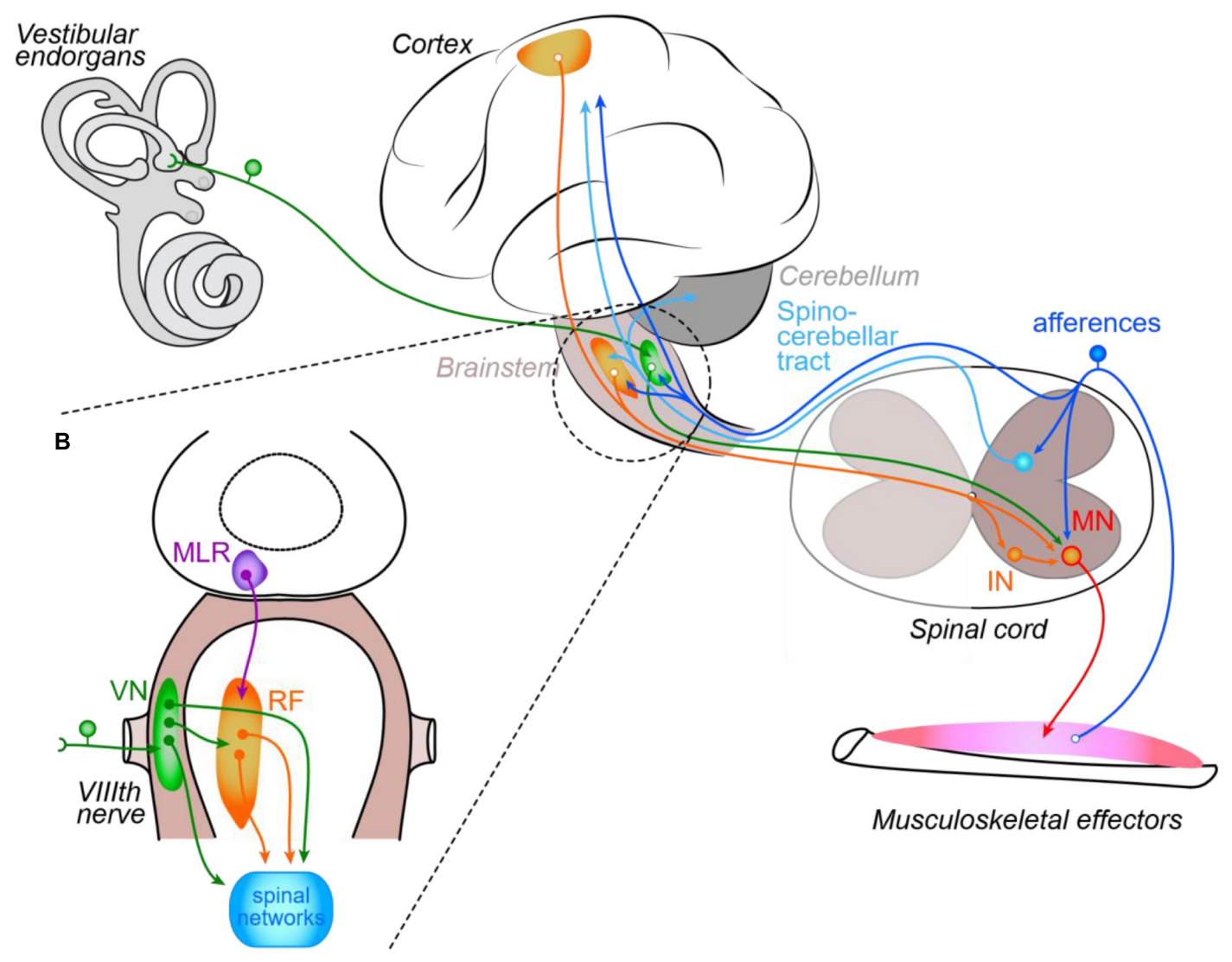

FIGURE 1 | Schematic organization of the control of posture and locomotion in vertebrates. Illustrated central and peripheral structures and connecting pathways (A) are arbitrarily limited to those discussed in the review. The inset (B) focuses on the main brainstem structures responsible for posturo-locomotor supraspinal commands. IN, interneuron; MN, motoneuron; MLR, mesencephalic locomotor region; VN, vestibular nuclei; RF, reticular formation; VIllth nerve, vestibular nerve.

(Falgairolle and Cazalets, 2007). However, similarly to fishes it remains quite impossible to ascertain that such back muscle activities are not also simply related to propulsion, which is made possible by the vertebral spine flexibility observed in the majority of vertebrate species. For example, during cheetah or greyhound run, cycles of spine curvature/extension strongly participate in the animal's propulsion (see Hudson et al., 2012).

Nonetheless, the particular anatomy of the vertebral column of post-metamorphic anuran Xenopus laevis (Beyeler et al., 2008) strongly limits spine flexibility. Indeed, propulsion is entirely provided by the hindlimbs, whereas the contraction of the axial back muscles dorsalis trunci generates only small twists of one vertebra with respect to the neighboring others, conferring these muscles a purely postural function (at least for myomeres 3 and 4 since their insertion on the skeleton prohibits any participation in propulsion; OlechowskiBessaguet et al., 2020). Electrophysiological recordings from either back muscles in vivo or dorsalis-innervating thoracic ventral roots in vitro showed strict coordination with hindlimb muscles/lumbar ventral roots activity during swimming, and thoracic MNs were likely directly activated by the lumbar CPG (Beyeler et al., 2008). Thus, in juvenile Xenopus at least, axial postural networks are subdued to propulsive networks through segmental propriospinal connections when the locomotor CPG is active, in order to generate the appropriate anticipatory postural adjustments necessary to ensure accurate locomotion.

\section{Sensory and Supra-Spinal Control of Spinal Networks}

Although intrinsic auto-organization of posturo-locomotor activities exists within spinal networks, these are modulated by both local sensory feedbacks and descending commands from supra-spinal structures (Figure 1; Grillner and El Manira, 2020). During locomotion, local sensory control is mediated by segmental proprioceptive and cutaneous afferents in a cycledependent manner (MacKinnon, 2018). For instance, loadmediating afferents (Ib) are implicated in joint extension while afferents that inform about muscle length variation (Ia afferents from muscle spindles) are mainly involved in joint movement termination and initiation of movement in the opposite direction, acting on the reciprocal inhibition between flexor and extensor (e.g., in humans: Perez et al., 2003). Cutaneous information is involved equally in locomotor and postural activities; notably 
during locomotion, they modulate the cycle by interacting presynaptically with other afferent signals. In turn, during locomotion sensory feedback afferents are cyclically modulated by the CPG via specialized inhibitory INs (reviewed in Côté et al., 2018). Descending commands from supra-spinal centers are also able to modulate spinal reflexes in a phase-dependent manner. In humans for example, increasing the postural threat during walking changes the gain of the H-reflex (Krauss and Misiaszek, 2007), which suggests that convergence of both local sensory and descending brain commands onto spinal INs (Stecina and Jankowska, 2007; Stecina et al., 2008) is essential to regulate local reflexes (Phadke et al., 2009). Nevertheless, even in spinalized cats (deprived of every supra-spinal inputs) walking on a treadmill, pace can gain symmetry if treadmill velocity is increased (Dambreville et al., 2015), indicating that spinal networks are nevertheless intrinsically able to adapt the motor program they produce as gait increases in speed, and this probably via the implication of the local, symmetrically organized sensory feedback networks.

Supra-spinal structures determine initiation and termination of locomotion, as well as gait adaptation to challenging milieus, in a cascade of commands sequentially involving cortical and thalamic structures, basal ganglia, mesencephalic nuclei and, finally, reticulospinal nuclei that directly control spinal CPGs (Grillner et al., 2008; Kozlov et al., 2009; Leiras et al., 2022). They are also responsible for a majority of postural commands, besides the propriospinal coordinating pathways involved in locomotion-required postural adjustments (see above). Among these structures, sensory-motor cortices, via bilateral crossed corticospinal tracts, are mostly implicated in the voluntary control of fine body and limb motion (see Takakusaki, 2017). In animals in which the cortex is much less developed, the fine control of movement seems to be achieved by the red nucleus (Olivares-Moreno et al., 2021), which is intimately interconnected with both the cortex and the cerebellum (Cacciola et al., 2019). Basal ganglia also participate in posture regulation, through projections on brainstem motor centers, including the mesencephalic locomotor region (MLR) and the reticular formation (Takakusaki et al., 2016). Within the brainstem (Figure 1B), vestibulospinal (VS) and reticulospinal (RS) nuclei play the major role, reticulospinal neurons relaying the great majority of higher posturo-locomotor commands from the MLR (as described in many details in the lamprey; see Le Ray et al., 2011) and cortex (Stecina and Jankowska, 2007) as well as inputs from the central vestibular nuclei (CVNs; e.g., Deliagina et al., 1992; Pflieger and Dubuc, 2004). Yet, in all vertebrates vestibulospinal neurons also directly activate spinal motor networks to ensure body postural adjustments and maintain head position in space (Straka and Baker, 2013; Cullen, 2016; Bagnall and Schoppik, 2018). In addition, CVN neurons affect indirectly the control of posture via their projections to the thalamus and insular cortex, as well as via their bilateral interactions with cerebellar nuclei (see Takakusaki, 2017; Cullen, 2019). The latter also directly and indirectly integrate vestibular afferents (Carpenter et al., 1972; Schniepp et al., 2017).

Many studies investigated the organization of vestibulospinal projections in various species, from lamprey
(Deliagina et al., 2014) to mammals (Kasumacic et al., 2015); however, only a recent work in the juvenile Xenopus clearly provided a functional and anatomical description of vestibulospinal projections onto spinal neurons specifically involved in the control of posture (Olechowski-Bessaguet et al., 2020). This study reports that vestibulospinal nuclei activate identified postural MNs through two distinct ways: the first, classically described in all species, consists of a direct activation of populations of spinal neurons (INs and MNs) involved in the control of posture at the segmental level (e.g., thoracic MNs activating dorsalis muscles), and conveys principally signals related to head position; the second, yet undescribed, consists of an indirect pathway to activate these same thoracic neurons via a lumbar interneuronal relay dispatching the vestibular command to thoracic and lumbar MNs simultaneously, and conveys mainly velocity signals from the vestibular system.

Whatever the species, central vestibular neurons integrate spatially corresponding, convergent vestibular, optokinetic, proprioceptive and cutaneous inputs, and it has been postulated that the vestibulospinal network anatomical organization included all sensory-motor transformations appropriate for the control of posture (Vidal et al., 1993). Interestingly, although working according to a "push-pull" mechanism (one side being inhibited when the other side is excited by a given direction of head movement) the vestibular system is symmetrically organized, and mathematical models have suggested that the bilateral symmetry of vestibular reflexes (notably the vestibulo-ocular reflex; Smith and Galiana, 1991) resulted from this symmetry in the vestibulo-motor system (e.g., Ris et al., 1995). In particular, vestibulospinal projections are anatomically organized in symmetry groups likely related to their physiological sensory-motor function (McCollum, 2007), providing the vestibulospinal system with a powerful capacity to adapt precisely spinal posturo-locomotor functions. However, similarly to segmental sensory feedbacks in the spinal cord, vestibular integration is subject to modulation during active movement (Chagnaud et al., 2015), notably via interactions with the cerebellum (Takahashi and Shinoda, 2021) and via bilateral ascending spino-bulbar pathways conveying an efference copy of the motor program generated by spinal networks. These latter ascending efferent copies were clearly demonstrated in both larval (Combes et al., 2008) and juvenile (von Uckermann et al., 2013) Xenopus to coordinate directly eye movements with locomotor-induced head displacements, and were proposed to exert side-specific filtering of vestibular sensory integration in the CVNs (Straka et al., 2018). Recent studies in human subjects provided evidence that comparable efference copy mechanisms may also account for the stabilization of eye vertical position, at least during fast locomotion (Dietrich and Wuehr, 2019; Dietrich et al., 2020).

\section{COMPENSATION AFTER A UNILATERAL LESION IN CENTRAL MOTOR CIRCUITS}

The anatomical and functional organization of the sensorymotor neural system involved in posture and locomotion is 
globally symmetrical, both at spinal and supra-spinal levels, fitting the gross symmetry of the biomechanical apparatus that ensures these functions. It is known that any loss in symmetry in either the neural or biomechanical arrangement would generate discrepancies between the two systems. Amputation or immobilization of a limb, for instance, will cause strong reorganization in various parts of the neural system (Bramati et al., 2019; Makin and Flor, 2020; Conboy et al., 2021; Raffin, 2021), while an accidental or pathological neural asymmetry will trigger plasticity in both the neural and biomechanical (e.g., muscle; Gorgey et al., 2019) systems. In the following, we will only review studies regarding neural plasticity and behavioral adaptation in response to damage-induced central asymmetry. One difficulty in understanding how the posturo-locomotor CNS copes with accidental central asymmetry resides in the fact that, depending on animal models and location of the lesion, various levels of recovery can be observed. For instance, fish and most amphibians are able to restore a substantial part of transected axons within the spinal cord (Noorimotlagh et al., 2017; Rasmussen and Sagasti, 2017; El-Daher and Becker, 2020), making these animals particular models of posturo-locomotor symmetry restoration that will not be considered in detail in the following. In addition, for comparable lesions in a given animal model, the motor activity generated below the lesion also largely depends on the internal state of excitability of the considered spinal networks and local sensory feedback, as well as of spared descending commands. Nevertheless, some general rules can be drawn from the vast literature in this domain.

\section{Structural Brain Plasticity After Unilateral Central Nervous System Lesions}

It has been long known that damages in the human sensorymotor cortex produce side-specific effects (Robinson, 1979), with acute lesions on the right side affecting mostly the control of posture while left side brain injuries rather generate apraxia (Spinazzola et al., 2003). As a primary response to unilateral stroke in the motor cortex, deep cortical reorganization occurs, as recently reported in patients with focal ischemic stroke where theta burst-induced depression was initially higher in the contralesional motor hemisphere and slowly recovered during the following weeks, whereas no changes were observed in the ipsilesional hemisphere (Hordacre et al., 2021). In rodents, stroke on one side of the sensory-motor cortex similarly triggers contralateral motor cortex plasticity (Takatsuru et al., 2009), but may as well affect the ipsilesional cortex. As shown in the adult rat, focal ischemic stroke in the motor cortex area controlling a forelimb initially generates motor deficits that are progressively compensated for, due to ipsilesional motor cortex neurons involved in hindlimb control sprouting new collaterals into cervical spinal motor circuitry (Figure 2; Starkey et al., 2012).

In contrast, a developmental alteration of the cerebellum symmetrical organization (unilateral hypoplasia) does not significantly modify postural and locomotor movement symmetry (Immisch et al., 2003) but globally slows down movements and delays motor skill acquisition in children (Benbir et al., 2011), suggesting that cerebellar symmetry is not a pre-requisite for accurate motor control. However, it has been shown in primates that, depending on the considered cerebellar network, a unilateral acute lesion oppositely affects nystagmus direction (Romano et al., 2020), suggesting that posture and eye movement rely on distinct neural organizations. In rats, posture is comparably affected by acute lesions of the sensory-motor cortex on either side; however, the reported asymmetry in hindlimb postural response seems to rely on distinct mechanisms, a right-side damage triggering spinal motor network reorganization, and a left-side lesion instead altering local sensory integration (Zhang et al., 2020).

As a result of spinal cord injury (SCI), disconnection of descending pathways that carry supra-spinal motor commands toward spinal motor networks generates postural and locomotor disturbances (e.g., reduced use of ipsilesional limb after unilateral rubrospinal tract lesion; Webb and Muir, 2003) that can be (partially) compensated for by downstream (see later) and/or upstream plasticity. Such plasticity can occur spontaneously but usually benefits from sensory-motor training similarly in patients and animals (Knikou, 2010; Torres-Espín et al., 2018; but see Fouad et al., 2000). In rats, SCI does not trigger damaged corticospinal neurons to degenerate (Nielson et al., 2010) but these are likely redeployed in new functional cortical networks. For instance, incomplete SCI at a cervical level leads to a transient loss of ipsilateral paw representation in the primary somatosensory cortex; this representation is reactivated (Ghosh et al., 2009; Martinez et al., 2010; Bazley et al., 2014) and tactile ability ameliorates with sensory-motor training protocols, mobilizing the preserved pathways and resulting in primary motor cortex reorganization (Martinez et al., 2009, 2010). On the contralesional side, consecutive to cord hemisection and bilateral dorsal column cut, motor cortex spiny pyramidal neurons exhibit tapered and longer dendrites, due to an overexpression of polysialylate cell adhesion molecules that limit synapse formation (Kim et al., 2006, 2008), indicating cellular reorganization in cortical networks. Finally, plasticity may occur as well in the lower brainstem, as recently investigated in lampreys (Hough et al., 2021) where spinal cord hemisection leads ipsilesional RS neurons to adapt their electrical properties, compared to contralateral uninjured RS neurons. However, such changes in intrinsic properties do not seem to affect the way these command neurons integrate input signals, notably sensory trigeminal inputs, raising the question of the functionality of such a plasticity and whether this participates in subsequent locomotor recovery.

\section{Functional Spinal Plasticity After Unilateral Spinal Cord Injury}

Spinal cord injured animals are common models for studying neural plasticity (Dietz and Fouad, 2014; Alizadeh et al., 2019) in the context of motor functions (respiration: Streeter et al., 2020; posture and locomotion: Brown and Martinez, 2019). Most species are capable of partial or complete recovery after SCI, demonstrating the intrinsic ability of spinal sensory-motor networks to organize functionally relevant motor commands even in the absence of part or all descending commands and 


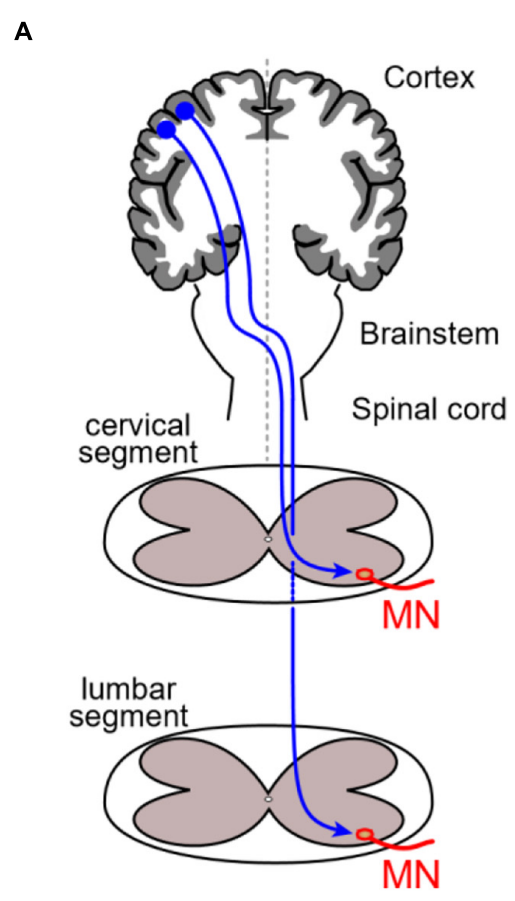

B

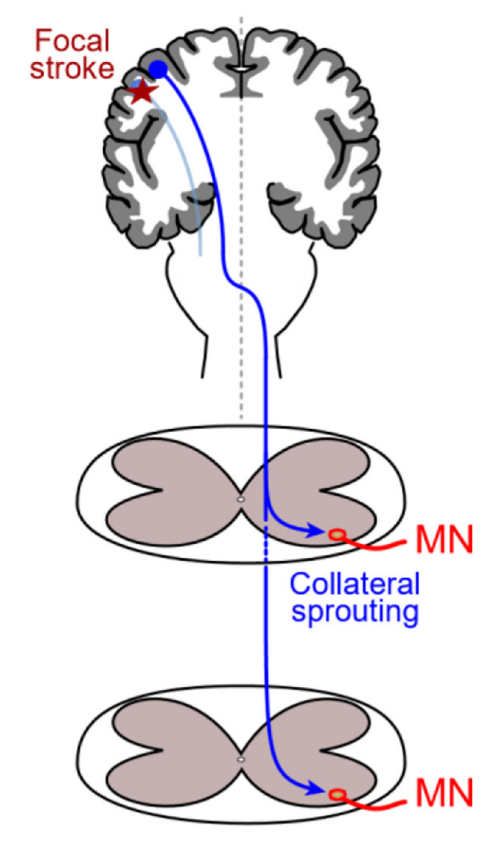

FIGURE 2 | Unilateral stroke-evoked corticospinal plasticity. (A) In normal rats, corticospinal neurons from sensory-motor areas (dark blue projections) specifically connect either cervical or lumbar spinal MNs respectively involved in fore- and hindlimb fine motricity. (B) After a focal stroke in the cortical region hosting neurons projecting into cervical segments (red star), forelimb-related corticospinal neurons degenerate (light blue), and hindlimb-related neurons normally projecting only onto lumbar MNs sprout collaterals that make synapse onto cervical MNs deprived of their normal corticospinal inputs.

neuromodulation (Rossignol et al., 1996; but see also Merlet et al., 2021). Lumbar SCIs are more deleterious than mid-thoracic ones as reported in cats (Rossignol et al., 2002) and rats (GarcíaAlías et al., 2006), probably because they may directly injure the locomotor CPG. In this context, spinal cord hemisection or incomplete SCI at a cervical or thoracic level provide interesting models to investigate the mechanisms by which a bilateral symmetrically built CNS adapts to abnormal imbalance, in order to maintain symmetrical biomechanics as accurate as possible. For instance, whereas a cervical cord hemisection induces the operational loss of the ipsilesional forelimb in rats, both hindlimbs recover coordinated activity compatible with functional locomotion (Ghosh et al., 2009).

In cats with unilateral thoracic SCI, after intensive motor training both the spinal CPG and sensory-motor connections exhibit deep remodeling (Barrière et al., 2008; Martinez et al., 2013), which results in the generation of motor command asymmetries downstream of the lesion to restore bilateral locomotion. In addition, such reorganized spinal networks persisted after a subsequent complete spinal cord transection, the latter transiently triggering opposite asymmetries before normalization (Barrière et al., 2008, 2010), which demonstrated that initial symmetry restoration was independent from descending influences. In contrast, other studies in animals (Singh et al., 2011) and humans (Edgerton et al., 2001) tend to suggest that recovery from unilateral SCI depends strictly on an interplay between contralesional descending pathways and local sensory feedback to enhance depolarization in spinal neurons below the lesion at least primarily; thereafter, when spinal circuits retrieve their ability to respond to descending commands without additional excitation, reflexes would be down-regulated (Little et al., 1999). Experiments in cats showed that restoration substantially relied on the asymmetrical integration of local reflexes, notably cutaneous-mediated reflexes (Helgren and Goldberger, 1993; Frigon et al., 2009) that were enhanced in the ipsilesional lumbar hemicord (Gossard et al., 2015). Similar implication of cutaneous inputs was also reported from thoracic hemisection experiments in the chick (Muir and Steeves, 1995; Muir et al., 1998), and conditioning the control of H-reflex amplitude on the ipsilateral side reduces motor asymmetry in rats, monkeys and humans (Wolpaw and Lee, 1989; Chen et al., 2006; Thompson and Wolpaw, 2015). In contrast, prior ankle denervation prevented symmetrical posturo-locomotor recovery in SCI cats (Carrier et al., 1997). All these results support a pivotal role for local sensory integration in the recovery of functional motor symmetry. Furthermore, mutant mice lacking proprioceptive feedback from muscles showed no recovery after a thoracic hemisection, and this was associated with a restricted and inaccurate reorganization of contralesional descending pathways below the lesion (Takeoka et al., 2014). This latter study thus suggests that if an interplay between descending pathways and local sensory feedback is required for the accurate reorganization of spinal networks after unilateral SCI, local sensory information likely orchestrates this interplay.

Plasticity is not limited to the restoration of hindlimb CPG operation. After a cervical hemisection, modifications were found 
A $\mathrm{A} 1$

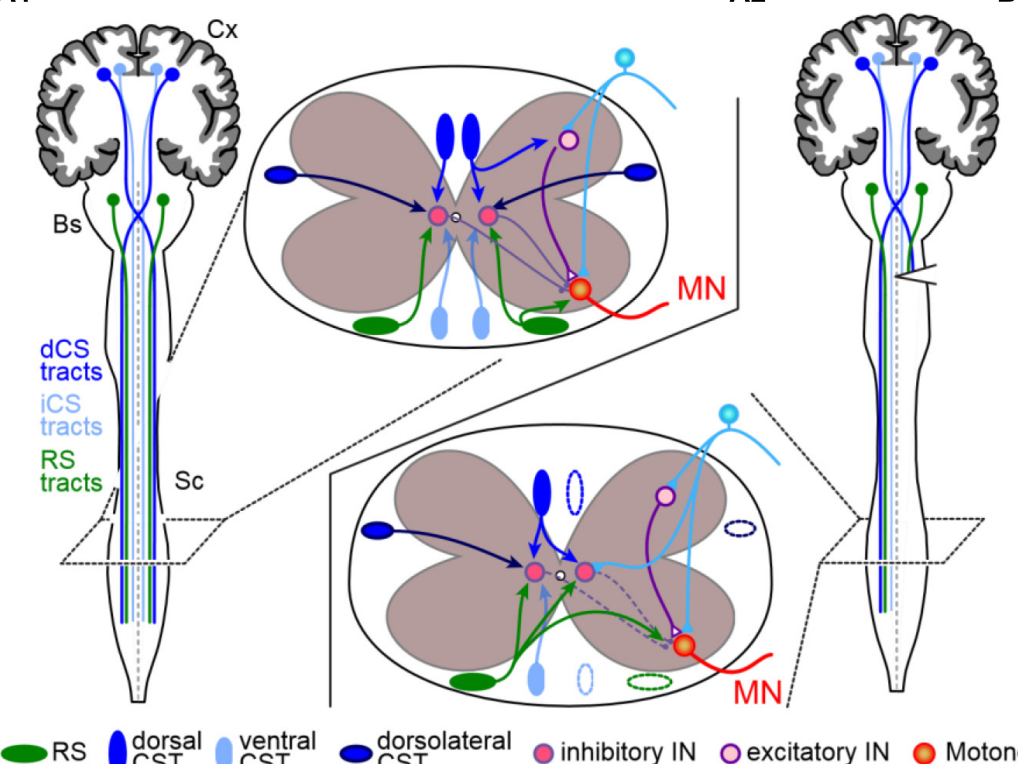

B

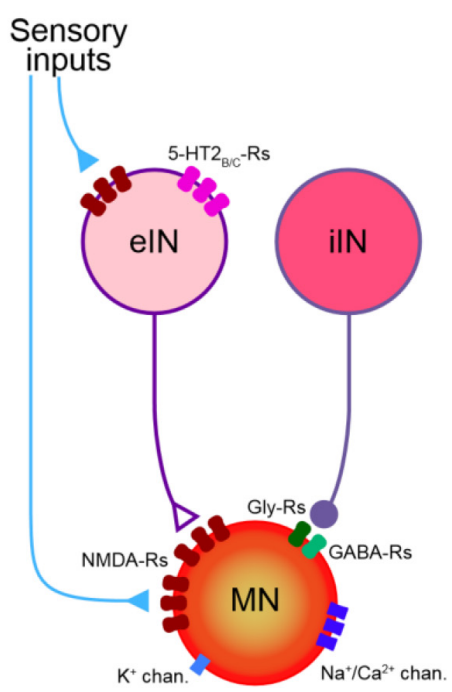

FIGURE 3 | Spinal network reorganization after unilateral spinal cord injury. (A) The symmetrical organization of uncrossed (light blue) and crossed (dark blue) corticospinal and reticulospinal (green) projections (illustrated in upper inset) and local sensory inputs (cyan) onto segmental INs (pink) and MN (orange) in control animal (A1) exhibit adaptations below spinal cord hemisection (A2) ipsilesional sensory inputs invade IN and MN dendritic territories deprived from their ipsilateral descending projections, and contralateral descending axons sprout terminals into the ipsilesional hemicord. See text for details. Cx, cortex; Bs, brainstem; Sc, spinal cord; iCS and dCS, ipsilateral and decussating corticospinal tracts; RS, reticulospinal. (B) SCl-induced acute modifications in motor neuron (MN) and excitatory and inhibitory interneurons (eIN and ilN, respectively) intrinsic and synaptic properties leading to MN hyper-excitability. Sensory-evoked responses are enhanced due to increased expression of NMDA receptors (NMDA-Rs) in both MN and eIN, and increased expression of serotonin receptors (5-HT2 ${ }_{B} / C^{-R s)}$ in elN. In contrast, inhibitory influences from ilN onto MN are reduced due to lower motoneuronal expression of GABA and glycine receptors (GABA-Rs and Gly-Rs, respectively). In addition, overexpression of sodium/calcium permeant channels ( $\mathrm{Na}^{+} / \mathrm{Ca}^{2+}$ chan.) and lower expression of potassium channels ( $\mathrm{K}^{+}$chan.) intrinsically increase $\mathrm{MN}$ excitability. The relative expression of membrane channels and receptors is illustrated as follows: one item shows a decrease and three items an increase compared to a "normal expression" of two items.

in the unaffected forelimb circuitry that compensated for the motor deficits in the harmed forelimb in adult rats (Khaing et al., 2012), and the bilateral propriospinal coordination between cervical and lumbar networks (respectively controlling forelimbs and hindlimbs) is changed in order to bilaterally restore the anteroposterior interlimb coordination in cats (Côté et al., 2012). Although significant posturo-locomotor recovery occurs, motor anomalies may nevertheless persist after incomplete SCI and subsequent training. In adult rats, for instance, persistent overlap between flexor and extensor muscle activities was reported and proposed to result from the existence of an asymmetry in descending pathways (Kaegi et al., 2001). However, the authors also reported a simultaneous improvement of stance and body support in lesioned animals, which suggested that what appeared to be an incomplete recovery might in fact consist of a compensatory motor adaptation to the loss of half of the descending motor commands. In fact, global reorganization of muscle activation pattern was similarly described where axial muscles below the lesion were found to participate more during pelvis and hindlimb movements in trained SCI rats (Giszter et al., 1998), as well as during phase shift in walking patients (Scivoletto et al., 2007). Such axial muscle plasticity further raises the question of why axial networks seem to be less affected by unilateral central lesions. An explanation may be found in the particular organization of descending commands onto these networks where pyramidal excitatory commands onto dorsal MNs are mainly relayed by RS neurons and inhibitory commands by spinal inhibitory INs located in the two hemicords. Such bilaterally distributed organization may account for the axial system greater resilience to unilateral pyramidectomy in cats (Galea et al., 2010).

\section{Unilateral Spinal Cord Injury-Induced Spinal Pathway Plasticity}

Because both ascending (principally sensory) and descending (motor) pathways are affected by SCI protocols, series of experiments with restrained spinal lesion were designed with the aim of clarifying the relative participation of different pathways in SCI acute effects and subsequent recovery. Hence, a joint unilateral destruction of dorsolateral funiculus (corticospinal and reticulospinal tracts) and ipsilateral dorsal columns (ascending sensory tract) had no long-lasting impact on posture and locomotion in adult rats. In contrast, it produced strong deleterious effects when combined with ventrolateral funiculus (principal reticulospinal tract) interruption (Loy et al., 2002), confirming the major role of RS neurons in the control of downstream motor networks. Such a role was further supported 
by the observation in rats that post-SCI locomotor recovery necessitated the preservation of at least part of spinal ventral and/or lateral white matter (Schucht et al., 2002). Furthermore, increased crossing of contralesional RS fibers and increased number of connections on local propriospinal INs were reported to develop below the hemisection site, together with increased responses of these RS neurons to stimulation of the contralesional MLR (Rangasamy, 2013; Zörner et al., 2014; Engmann et al., 2020). This suggests that plasticity in brainstem motor command circuitry occurs to compensate the functional loss of a half of command neurons while spared RS neuron projections reorganize to restore functional symmetry in projection pathways below the lesion (Figure 3A).

In contrast, after unilateral spinal hemisection no significant changes were globally found in cortico- and vestibulospinal tracts, and only a small tendency of increased rubrospinal fiber crossing was reported (Zörner et al., 2014). However, selective spinal lesion targeting the decussating corticospinal tract on one side induced motor deficits that recovered rapidly in rats (Bazley et al., 2012). This was paralleled by the induction of new connections between corticospinal terminals and longprojecting propriospinal INs that connected lumbar MNs (Bareyre et al., 2004), the outgrowth of ipsilaterally projecting corticospinal fibers into sub-lesion cord segments, as well as sprouting of ipsilesional sensory afferents within the ventral cord territories that lost their corticospinal inputs (Figure 3A; Bareyre et al., 2002; Brus-Ramer et al., 2007; Tan et al., 2012). The establishment of new corticospinal connections and subsequent motor recovery are prevented in mutant mice expressing inhibitory DREADDs in spinal INs, demonstrating that this process depends on the presence of activity in local INs, likely induced by segmental sensory afferent activation of NMDA receptors (Bradley et al., 2019). Consecutive to sensorymotor cortex unilateral stroke (which causes corticospinal neuron degeneration) hindlimb stretch reflexes were found to be enhanced and some plasticity genes (e.g., Grin2a/DLg4 and Tgfb1) inversely regulated in adult rat lumbar segments (Zhang et al., 2020). This study suggests that one important function for sensory-motor cortex neurons projecting to the spinal cord is to regulate plastic adaptation of local spinal reflexes during ongoing posturo-locomotor activity. Indeed, phase-dependent depression of reflex loops was found to be reduced following incomplete SCI and able to recover, in a neurotrophic factor-dependent manner (Côté et al., 2011), in response to spared corticospinal pathway stimulation (Brus-Ramer et al., 2007; Petrosyan et al., 2020) or sensory-motor training (Phadke et al., 2009; Côté et al., 2011). Corticospinal damage-induced spinal reorganization acutely leads to spinal hyperreflexia, which has been considered as maladaptive (Tan et al., 2012), though such hyperreflexia may participate actively in the process of posturo-locomotor recovery by increasing the overall excitability of spinal networks below the lesion site (see below).

Dorsal hemisection, which suppress half of sensory inputs ascending to brain centers, has dramatic acute effects on locomotion, affecting notably paw placing during skilled walking, until sensory afferent reorganization within the ipsilesional hemicord occurs and allows functional recovery. In mice with such lesions, ascending dorsal root neurons increased branching below the lesion site and, in particular, connected propriospinal INs projecting into the cuneate nucleus, constituting so a detour circuit to brainstem centers (Granier et al., 2020), and beyond, to the primary sensory-motor cortex (as afore suggested in rats and monkeys; Kaas et al., 2008). Functional restoration of bilateral tactile and proprioceptive sensation occurred in these animals within weeks, demonstrating the exceptional ability of sensory systems to compensate for selective alterations of their central pathways. In contrast, adaptation of central motor commands to unilateral sensory loss noticeably takes much longer to reorganize. Indeed, it was shown in macaque monkeys that a unilateral dorsal rhizotomy at the cervical level (which completely removed sensory inputs from one forelimb) triggered a complete loss of grasp in the corresponding forelimb that persisted over several months. With time, functional recovery nevertheless occurred and was paralleled by the anatomical reorganization of corticospinal projections into cervical segments from both the primary somatosensory and motor cortices (Darian-Smith et al., 2013; Nardone et al., 2013); however, while the former displayed clear retraction from the cervical hemicord, the latter exhibited abnormal sprouting in the ipsilesional dorsal horn (Darian-Smith et al., 2013; but see also Darian-Smith et al., 2014). These works demonstrate that a unilateral sensory deprivation causes rearrangement of different corticospinal projections, and further suggest a distinct implication of each corticospinal tract in motor recovery that remains unexplained.

\section{Cellular Mechanisms of Unilateral Spinal Cord Injury-Induced Spinal Network Plasticity}

Whereas the effects of cord hemisection on directly lesioned tissues are well documented (Ahuja et al., 2017), the cellular impacts on downstream motor networks in relation with the observed behavioral consequences is still not clear, and some aspects have not been explored to date. For example, the astrocyte role in SCI-induced formation of glial scars (astrocytic reaction) has been analyzed extensively at the lesion level itself (Okada et al., 2018). Surprisingly, even though they are known to regulate activity of locomotor networks in physiological conditions (e.g., $\mathrm{Mu}$ et al., 2019) the potential implication of astrocytes in post-SCI motor adaptation remains undocumented. In contrast, numerous investigations in various species have analyzed the neuronal mechanisms involved in motor restoration. In injured lampreys, spinal neurons below the lesion exhibited increased resting membrane potential as well as increased input resistance that, combined with synaptic efficacy enhancement, strongly improved neuronal excitability (Cooke and Parker, 2009). In adult rats with cervical cord hemisection, Gonzalez-Rothi and colleagues reported the transient development of muscular atrophy in the corresponding forelimb (Gonzalez-Rothi et al., 2016), which could have suggested a deficit in motor command due to dramatic and maladaptive rearrangement of spinal motor and/or premotor neurons. But, using pseudorabies viruses during the same period of time in order to track putative added/subtracted connections, the authors did not observe any 
obvious changes in first-order premotor IN-MN circuitry of the cervical cord (Gonzalez-Rothi et al., 2015), suggesting that no dramatic premotor network reorganization occurred that could explain muscle atrophy-related reduced motoneuronal activity, nor its recovery with time. Furthermore, it was shown in mice that genetically identified V2a (Shox2) INs, which are putative constituents of the lumbar CPG, conserved their intrinsic resting membrane properties after SCI (Husch et al., 2012). However, these INs exhibited increased excitability due to enhanced efficacy of both local sensory and descending monoaminergic input synapses, as well as more intense expression and increased sensitivity of $5-\mathrm{HT}_{2 B} / 2 C$ receptors (Figure 3B; Husch et al., 2012; Garcia-Ramirez et al., 2021). Noteworthy, these serotonin receptors facilitate synaptic input-evoked responses of spinal neurons, likely by modulating calcium channels sustaining plateau potentials (Perrier et al., 2013). Taken together, it seems that spinal INs are only minimally affected by spinal hemisection, suggesting a subsequent minor role in motor symmetry restoration. Nevertheless, because these INs integrate inputs from both local sensory afferents and descending projections from brainstem command centers, which both exhibit deep adaptation (see above), it is likely that plasticity at IN input synapses would allow more efficient network operation. Hence, increasing inhibition from commissural INs would participate in the restoration of bilateral coordination, while enhanced ipsilateral inhibition would participate in reducing $\mathrm{MN}$ hyperexcitability and in shaping new adapted coordination.

In contrast, diverse modifications were reported in MNs in rodents which underwent SCI (Figure 3B). Sub-lesion MNs were characterized by increased expression of sustained $\mathrm{Na}$ /Ca-dependent plateau potentials (Li et al., 2004; Heckman et al., 2005) and NMDA receptors (Gransee et al., 2017), both increasing $\mathrm{MN}$ responses to excitatory synaptic inputs. Moreover, structural alterations of motoneuronal input synapses favoring $\mathrm{MN}$ excitability were reported in the lamprey (Cooke and Parker, 2009), and a reduction of potassium conductances occurs in ipsilesional leg MNs after unilateral interruption of the corticospinal tract in human patients (Jankelowitz et al., 2007). Rodent sub-lesional MNs were also shown to express less chloride transporters KCC2 at their plasma membrane, which diminishes the impact of the inhibitory inputs they integrate (Boulenguez et al., 2010). Moreover, SCI triggered a decreased expression of membrane receptors to inhibitory neurotransmitters GABA and glycine in downstream MNs (Sadlaoud et al., 2010, 2020), which modifies motoneuronal integration of inhibitory inputs (de Leon et al., 1999). Globally, this combination of compensatory changes in motoneuronal properties results in a dramatic increase in $\mathrm{MN}$ excitability. One may ask whether changes in MN dendritic morphology could happen after a cord hemisection, since modified dendritic arbors were reported in lumbar MNs from rats with complete thoracic transection (Gazula et al., 2004). Noteworthy, phrenic MNs do not exhibit morphology changes after a cervical hemisection, whereas it is the case after complete activity blockade with tetrodotoxin (Mantilla et al., 2018). Thus, dendritic morphology likely is directly linked to overall activity rather than to precise input synapses. As a consequence, because cord hemisection globally increases neuronal activity we may not expect significant dendritic morphology changes in sub-lesion MNs. Interestingly, it has been reported from mice that acute thoracic hemisection reduced the number of input synapses onto MNs located upstream of the lesion (Goldshmit et al., 2008), an effect that was reversed by motor training. This latter result demonstrates that MNs throughout the spinal cord are subject to plasticity in response to localized SCI and further support the idea that global symmetry restoration in posturo-locomotor functions likely depends on cellular modifications spreading all over central motor circuits.

Either the large majority of studies until now have focused on $\mathrm{MN}$ properties and very few on IN ones (yet, see the demonstration of IN neurotransmitter switching in the autonomic system after spinal lesion; Hou et al., 2016) or the principal cellular target of unilateral SCI-triggered plasticity is the MN. This gap in knowledge questions the inhibitory network modification that has been proposed to account for the alteration of sensory integration in humans with incomplete SCI (Knikou, 2012), which could finally result also/instead from changes in motoneuronal integrative processes below the lesion as shown in adult rats (Sadlaoud et al., 2020). Further investigations at the cellular level will be necessary to unravel the relative participation of network INs and output MNs in motor recovery after unilateral SCI.

\section{COMPENSATION AFTER UNILATERAL SENSORY LESION, WITH AN EMPHASIS ON THE UNILATERAL LOSS OF VESTIBULAR INPUTS}

Altering sensory integrity induces the functional and anatomical reorganization of cortical maps (Buonomano and Merzenich, 1998; Power and Schlaggar, 2017) as well as functional adaptations in motor circuits both at the spinal and supraspinal levels (Rossignol, 2006), which allows the restauration of postural and locomotor controls. For example, hindlimb deafferentation in cat acutely causes severe motor deficits that are largely compensated for with time. However, whereas the basic locomotor program generated by spinal CPGs is rapidly improved, step accuracy recovery requires several additional days and involves the joint implication of sensory afferents from the thoracic postural sensory-motor system (Goldberger, 1977) and various motor commands descending from the brain. This gave rise to the initial idea that motor adaptation to sensory deprivation resulted from 'behavioral substitution' rather than network remodeling (Goldberger, 1988). Supporting this hypothesis, the experimental deafferentation of one leg in healthy humans bilaterally modified leg biomechanics (Thoumie and Do, 1996) and bilaterally altered flexor and extensor muscle activation, resulting in postural adaptation by which the center of pressure was displaced backward under the ipsilesional foot (Imai et al., 2005).

There are also many studies which have identified configurational changes in various parts of the CNS following unilateral sensory deprivation. In that respect, a dorsal rhizotomy 
at cervical level $\mathrm{C} 4-\mathrm{C} 8$ in adult rats was shown to reduce specifically the representation of corresponding forelimb distal joints (mostly replaced by elbow representation) in the contralesional cortex, without changing the stimulation threshold to evoke left finger movements, nor affecting the cortical representation of any other limb (Jiang et al., 2013). Functional imaging in healthy subjects showed that acute deafferentation of a limb similarly induces cortical map reorganization. Indeed, an ischemic nerve block suppressing all distal afferent feedback from the left arm triggered a reversible expansion of the area in the left primary sensory-motor cortex that is activated during right finger movement and, as expected, the disappearance of responses to left finger stimulation (Kurabe et al., 2014). In the same way, in lamprey, crushing the trigeminal afferent nerve on one side induced a transient loss of touchevoked escape response that was recovered due to partial anatomical restauration of the lesioned sensory fibers and return of bilaterally normal RS neuron responses (Calton et al., 1998). Likewise, crushing a sciatic nerve in newborn rats is followed by a motor reinnervation of leg muscles after several months. However, muscle activation remains definitively inaccurate, with permanent alteration of stretch reflexes (Alvarez et al., 2010) and aberrant activation of ipsilesional flexor muscles during quiet stance as well as during extensor phase when the animal walked (Vejsada et al., 1991). Because muscle spindles do not regenerate, it is likely that the absence of sensory feedback on the lesioned side prevented a complete adaptation to occur. Thus, it appears globally that central networks are more or less able to adapt to an asymmetrical loss of motor-related sensory inputs, although the underlying cellular mechanisms remain usually unraveled. Yet, the effects of a unilateral vestibular deprivation (UVD) and the subsequent cellular events that lead to motor recovery have been quite well described in many vertebrate species. The following of this chapter will focus on this particular sensory deprivation in which acute effects were clearly separated from chronic, compensated ones.

\section{Early Unilateral Vestibular Deprivation-Induced Modifications Behavioral Consequences}

Alterations of both static and dynamic vestibular reflexes are comparably observed immediately after unilateral vestibular neurectomy (suppressing also the Scarpa vestibular ganglion) or peripheral endorgan destruction (labyrinthectomy) in humans and animal models (Lacour et al., 2016; Simon et al., 2020). Static deficits affect both posture (head and body tilt toward the lesioned side), eye position (spontaneous nystagmus), as well as perception leading to vertigo in humans (tilt of vertical estimation). In the following, we will address only UVD-induced posturo-locomotor deficits and the related cellular mechanisms implicated during acute and chronic (compensated) phase. For complete information about vestibulo-ocular function and pathways and UVD-induced plasticity, see Straka and Dieringer (2004); Beraneck and Idoux (2012), and Cullen (2016).

Posturo-locomotor deficits were proposed to result from the loss of both otolith and semi-circular canal information
(Mbongo et al., 2005). Yet, utricle selective ablation in terrestrial frogs reproduces postural deficits (Straka and Dieringer, 1995), whereas all motor deficits are observed in rats where only canal signals are impaired by the use of canal plugs (Geisler et al., 1997). Altogether, canal information may be the predominant signal for head stabilization in animals (including humans) whose head acquired additional mobility with respect to the thorax, while otolithic signals have prominence in the control of body vertical orientation in all species (Fritzsch et al., 2014). Whereas static deficits are rapidly compensated for (about a week post-lesion in animal models, up to 3 months in humans; Lacour et al., 2016), vestibular-related reflexes never totally recover, with the gain of vestibulo-ocular reflexes remaining lower than control, and postural adjustment enduring persistent deficits in challenging situations (Vidal et al., 1998).

\section{Central Vestibular Alterations}

Posturo-locomotor dysfunctions induced by a unilateral vestibular alteration result primarily from the disequilibrium that is generated by asymmetrical activity between ipsi- and contralesional vestibular nuclei (note that in simpler models such as the lamprey, UVD mainly generates imbalance in the RS system characterized by a net reduction of excitation in contralesional RS nuclei - Deliagina, 1997). Studies in UVD models demonstrated that acute disequilibrium results from a net reduction of spontaneous activity in ipsilesional CVN neurons due to the conjunction of reduced excitation because of sensory afferent loss and increased commissural inhibition from contralateral secondary vestibular neurons (Figure 4A).

Ipsilesional vestibular afferents were found to degenerate after the combined suppression of vestibular endorgans and Scarpa ganglion in anurans (Kunkel and Dieringer, 1994; Lambert et al., 2013) as well as after neurectomy in cats (Schuknecht, 1982) where the number of synaptic contacts onto ipsilesional CVN neurons drops by about one third (Raymond et al., 1991). Rapid and global metabolism reduction in ipsilesional CVNs was observed as soon as $3.5 \mathrm{~h}$ post-UVD in rats (Luyten et al., 1986; Paterson et al., 2006) and $2 \mathrm{~h}$ in cats (Maeda, 1988), indicating that spontaneous neuronal activity dramatically dropped in ipsilesional CVNs consecutive to afferent loss. In guinea pigs the proportion of ipsilesional 'silent units' after acute labyrinthectomy was estimated to be around $70 \%$ in the superior, lateral and medial nuclei (respectively SVN, LVN, and MVN), while the remaining active neurons displayed firing rates lower than controls (Ris et al., 1995; Ris and Godaux, 1998; Vibert et al., 1999a). Furthermore, neurons recorded from all ipsilesional CVNs still exhibited low firing responses to head rotation 1 week after the lesion (Ris et al., 1995). Patterns of silencing in ipsilesional CVNs were similarly reported from cats (Precht et al., 1966) and gerbils (Newlands and Perachio, 1990). In contrast, rostral MVN neurons on the lesioned side displayed an increased resting firing rate $4 \mathrm{~h}$ after UVD in rats (Yamanaka et al., 2000), which may explain the faster recovery from UVD observed in this species.

The cellular mechanisms responsible for ipsilesional CVN neuron depression early after UVD are not fully understood. A recent study in cats showed that the expression of small 


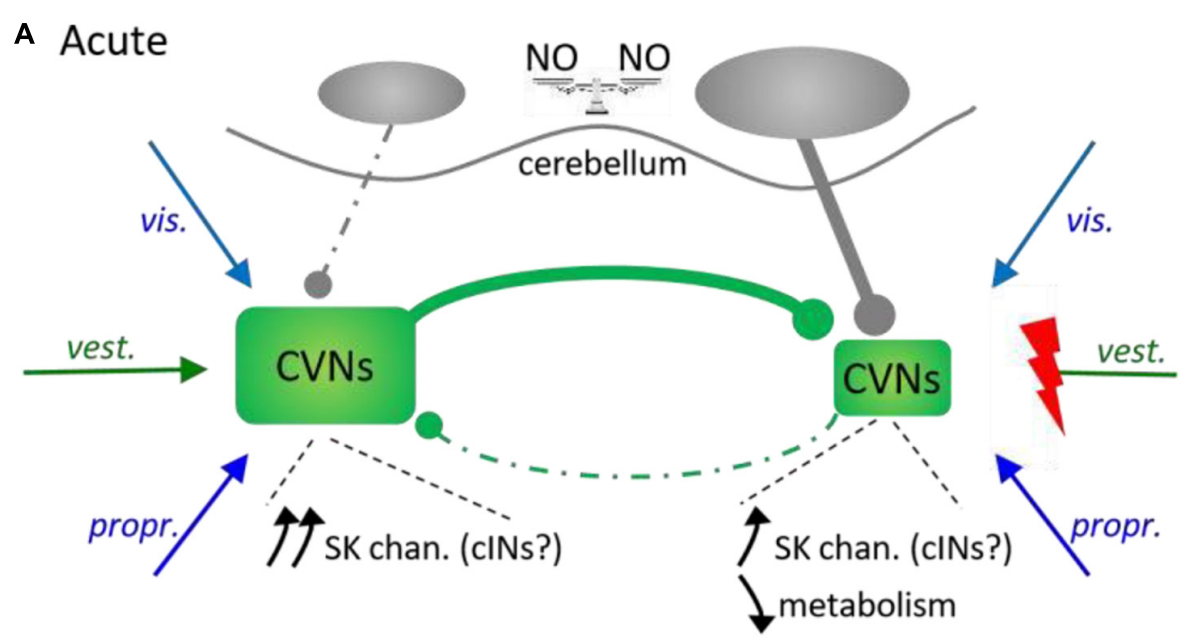

B Compensated

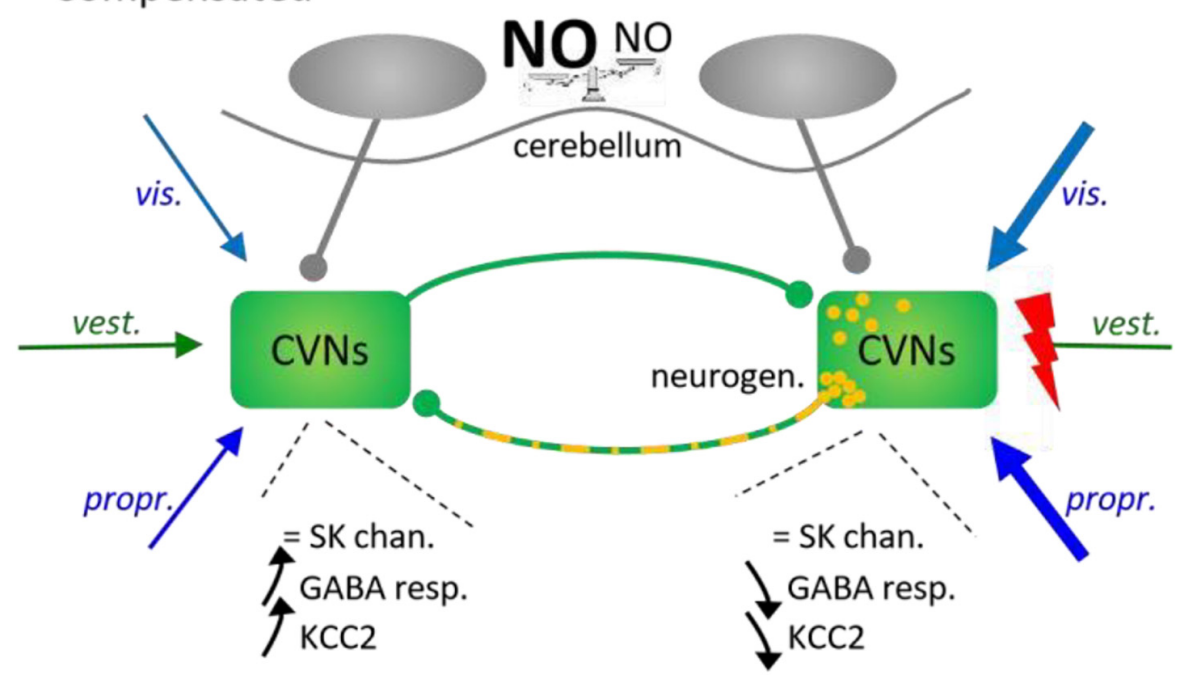

FIGURE 4 | Unilateral vestibular deprivation-induced adaptations in central vestibular nuclei and cerebellum. (A) Acute effects. A unilateral loss of vestibular afferents (vest.) triggers a rapid decrease in ipsilesional CVN neurons activity due to conjoint intrinsic and metabolic modifications together with increased inhibition from contralateral central vestibular nuclei (CVNs) and ipsilateral cerebellar nuclei. Although intrinsic properties of CVN neurons change bilaterally, net effect consists of a disequilibrium in reciprocal inhibition through commissural vestibular pathways (CINs) resulting in a stronger inhibition of ipsilesional CVNs. vis., propr., visual and proprioceptive afferents; NO, nitric oxide. Dotted lines: underactivated influences. (B) Compensated cerebello-vestibular network. Restoration of bilateral balance results from additional changes in intrinsic and synaptic properties of $\mathrm{CVN}$ neurons on both sides, together with ipsilesional GABAergic neurogenesis (yellow dots) and increased synaptic weight of both visual and proprioceptive inputs onto ipsilesional CVNs. Bilateral balance restoration also occurs in cerebellar nuclei due to a relative increase in $\mathrm{NO}$ on the contralesional side.

conductance potassium (SK) channels involved in post-discharge after-hyperpolarization rapidly rose in MVN, SVN, and LVN neurons during the first week following the lesion (Tighilet et al., 2019). SK channels expression was higher in contralesional CVNs and, although a neuronal phenotypic identification was lacking, both inhibitory and excitatory neurons were probably concerned. Such a disequilibrium in the expression of SK channels was proposed to affect notably commissural neurons and to account for balance loss between ipsi- and contralesional activity levels. Interestingly, it has been previously shown in cats (Cass and Goshgarian, 1990; Tighilet et al., 2007), guinea pigs (Rickmann et al., 1995) and rats (De Waele et al., 1996) that UVD induced both gliogenesis and increased astrocytic activity in CVNs in the first post-lesion days; given that astrocytes are essential components for extracellular glutamate and potassium homeostasis (reviewed in Walz, 2000), such a concomitant upregulation of SK channels in CVN neurons and increased astrocytic activity would ensure the CVN protection against hyperactivity-induced excitotoxicity and likely participate in the later bilateral activity re-equilibration (see below). In addition, as early as 3 days post-UVD, neurogenesis of neurons, mostly GABAergic, was also reported in cats to occur principally in the deafferented LVN, and to a lesser extent MVN and SVN (Tighilet et al., 2007; Tighilet and Chabbert, 2019), suggesting a possible role in the early decline of ipsilesional CVN activity (for a review on GABA effects on CVNs activity, see Gliddon et al., 2005). 
In addition, the strong reduction of ipsilesional spontaneous activity may consequently relieve contralesional CVNs from the commissural inhibitory control normally exerted by ipsilesional CVNs, making contralesional CVN neurons more spontaneously active. In turn, contralateral CVNs hence activated would exert in a stronger fashion their inhibitory (commissural) control on their ipsilesional counterparts, sustaining so the low excitability of ipsilesional CVN neurons. Though, a very recent study using optogenetics in mice suggested that an imbalance between the left and right MVN glutamatergic neurons might be the main source of deleterious effects of UVD on posture and locomotion, whereas GABAergic neuron selective activation had no clear impact (Montardy et al., 2021). Counter-intuitively with a reduction of activity in ipsilesional CVNs, mRNAs for NMDA receptor subunits NR1 and NR2C increased in the ipsilesional MVN of guinea pigs soon after UVD (Sans et al., 1997), which could suggest the instauration of a new complex balance between excitation and inhibition in CVNs following UVD; yet, because the nature of the cells expressing higher levels of NMDA subunit mRNAs was not identified, one may expect that such NMDA receptor overexpression could occur specifically in local inhibitory INs, increasing so their responsiveness to synaptic inputs and subsequently the inhibition of their target cells (as suggested by the work of Kitahara et al., 1995).

\section{Associated Brain Structures}

A UVD also affects the other CNS integrative structures implicated in the vestibular control of posture and locomotion. The loss of vestibular sensory information rapidly triggers widespread CNS adaptions, putatively in order to increase the weight of other sensory signals in the global sensory information used to operate posturo-locomotor functions. Supporting this idea, a very recent study in rats demonstrated that cortical somatosensory maps reorganized over the first hours following UVD, with bilateral expansion of the cutaneous receptive fields corresponding to the two hind paws and increased neuronal sensitivity to cutaneous stimulation (Facchini et al., 2021). Another example in rats comes from the cerebellum where a unilateral damage of the semicircular canal hair cells induced metabolic imbalance in the nodular cortex, characterized by an increase in glucose consumption on the ipsilesional side and a decrease on the contralateral side (Patrickson et al., 1985). This indicated that such a UVD had triggered activity imbalance between left and right nodules. Similarly, acute increases in nitric oxide (NO) synthesis enzymes were observed consecutive to UVD in the flocculus of rats (Kitahara et al., 1997a) and frogs Rana esculenta (Pisu et al., 2002), which indicated that plasticity occurred in this cerebellar subdivision particularly implicated in the integration of vestibular inputs (Figure 4A). While such increases were found bilaterally in these two species, they were always higher on the ipsilesional side. Furthermore, higher NO activity in cerebellar flocculus had been linked to concomitant reduction of the activation of contralesional CVNs and enhanced activity in the ipsilesional ones (Kitahara et al., 1999), which could participate in the later bilateral re-equilibration between CVNs (see below).

\section{Spinal Cord}

Surprisingly, given their fundamental role in locomotor and postural activity organization, very few is known about how spinal networks are acutely affected by a UVD. A functional hypo-activation of the ipsilateral soleus $\mathrm{H}$-reflex has nevertheless been reported to occur shortly (less than 2 days) after a UVD in the alert baboon while contralateral reflexes were enhanced (Lacour et al., 1976). The ipsilesional reflex reduction was proposed to result mainly from hypo-excitability of both $\alpha$ and $\gamma$ motoneurons, suggesting that spinal neurons are indeed affected in an early time window following UVD.

\section{Late Unilateral Vestibular Deprivation-Induced Modifications - The 'Vestibular Compensation'}

Early events that evoke vestibular imbalance are followed, with variable timelines depending on the considered species, by further plasticity mechanisms leading to a nearly full recovery of static head and trunk posture while dynamic deficits are never fully restored. Supposedly, these mechanisms constitute the substrate for the so-called 'vestibular compensation', taking place in every different structure mentioned above and resulting in the re-equilibration of $\mathrm{CVN}$ neuronal resting discharge on the two sides (Ris et al., 1997; Vibert et al., 1999b). At the CVN level, the restoration of balance results principally from modifications in the connectivity and efficacy of both sensory and commissural vestibular connections associated with changes in intrinsic properties of secondary vestibular neurons on the side of the lesion (Figure 4B). Such a combination of pathway reorganization and post-lesional cellular plasticity was suggested to account for the correction of static syndromes (see Lambert and Straka, 2012).

\section{Sensory Substitution}

Restoration of functional balance would be enhanced notably by substituting the lost vestibular signals with visual (e.g., Carcaud et al., 2017) and proprioceptive information (e.g., Jamali et al., 2014), which are also integrated by brainstem nuclei.

Interaction between visual and vestibular afferent signals were particularly well studied in the context of vestibulo-ocular reflexes where visual stimuli were found to regulate the reflex gain acting directly on secondary vestibular neuron intrinsic and synaptic properties (Carcaud et al., 2017). Whereas cellular mechanisms were much less analyzed in the context of posture control, several studies nevertheless demonstrated the substantial participation of visual stimuli in UVD compensation. In the lamprey, for example, UVD-evoked RS imbalance can be counteracted by stimulating the contralesional eye. Indeed, because ipsilesional RS nuclei still receive vestibular signals arising from the intact contralateral endorgans, the visually generated synaptic inputs impacting only upon contralesional RS nuclei restores the bilateral RS excitation balance (Deliagina, 1997). In contrast, suppressing movement-related visual information in UVD cats, by housing them for 2 weeks in a stroboscopic environment (Zennou-Azogui et al., 1996) or in darkness (Putkonen et al., 1977), was found to delay vestibular 
compensation. Similarly, stabilizing the visual environment with respect to the animal's head delayed as well the occurrence of compensation in UVD baboons (Lacour and Xerri, 1980), suggesting a role for the motion-related visual flux in correcting activity balance between bilateral CVNs. Vision seems to be fundamental as well in maintaining compensation in cats since UVD cats put into darkness after vestibular compensation display the characteristic head tilt of UVD animals, an effect that rapidly disappears after return into light (Putkonen et al., 1977). However, a recent meta-analysis of vestibular compensation bibliography in UVD animals revealed that, overall in mammals, vision has a limited impact on the increase in intrinsic excitability of ipsilesional CVN neurons (Wijesinghe and Camp, 2020) and the homeostatic recovery of bilateral CVN symmetry.

In contrast, lifting guinea-pigs from the ground early after UVD dramatically delayed the recovery of postural symmetry (Schaefer and Meyer, 1973). Similarly, restraining baboons made UVD-induced postural disorders to be compensated much later (Lacour et al., 1976). These results indicate that locomotor activity facilitates vestibular compensation processes, likely by generating movement-related proprioceptive and cutaneous information used to feed deafferented CVNs. Moreover, the increase in density (Dieringer et al., 1984) and weight of proprioceptive projections ascending from the spinal cord onto vestibular nuclei (Sadeghi et al., 2011) also seems to be a key element in maintaining posture correction in compensated UVD animals. Indeed, deprivation of brainstem nuclei from sensory feedback by suppressing ground contact or disconnecting ascending lateral tracts including spino-vestibular fascicle triggered static symptoms reappearance after compensation in rats and guinea pigs (Azzena, 1969; Jensen, 1979b; Schaefer et al., 1979).

Although reported from distinct animal species these results taken together suggest that an interplay between vision and proprioception may be the key mechanism involved in substitution for the lacking vestibular sensory information in UVD animals. It is noteworthy, however, that the time course of vestibular sensory deprivation directly impacts the ability to use visual cues for motor deficit compensation, as observed in human patients where a fast unilateral loss of vestibular information results in lesser visual dependence and stronger inability to maintain postural stability (Tjernström et al., 2019). In addition, after partial vestibular lesion the modification of both the organization and weight of residual vestibular afferents onto CVN neurons (Goto et al., 2002) as well as the possibility of peripheral plasticity in vestibular endorgans (Gaboyard-Niay et al., 2016) certainly participate in CVN adaptation and subsequent posturo-locomotor recovery (Cassel et al., 2018). Indeed, the degree of proprioceptive information utilization to control posture in UVD patients increase with their inability to use residual vestibular information (Peterka et al., 2011). To date, however, the cellular and synaptic mechanisms leading CVN neurons to adapt the relative weight of various sensory input signals in order to restore body symmetry remain unraveled.

\section{Central Vestibular Neurons}

A variety of post-lesional plasticity cellular processes were described in various vertebrate species that were proposed to account for the restoration of resting activity in ipsilesional vestibular nuclei and the resultant vestibular system re-balancing. Indeed, long-term vestibular compensation results in the reequilibration of resting activity between CVNs on the two sides (e.g., Darlington et al., 1989; Newlands and Perachio, 1990; Beraneck et al., 2003; Beraneck and Idoux, 2012) or between bilateral RS nuclei in the lamprey (Pavlova et al., 2004). In guinea pigs developing post-UVD compensation, intracellularly recorded ipsilesional MVN neurons exhibited pacemaker properties conferring the inherent ability to generate spontaneous activity (Darlington et al., 1989). This observation indicated that compensation did not result exclusively from modifications of input synapses, notably sensory input synapses (see above), but also from plastic changes in CVN neurons' intrinsic properties (Vibert et al., 1999b; Beraneck and Idoux, 2012). In cats, the overexpression of SK channels rapidly observed after UVD faded with time during the compensation process and re-equilibrated between CVNs on both sides (Tighilet et al., 2019). Because intrinsic properties could be modulated by the variety of neurotransmitters and neuromodulators environing CVNs (Darlington et al., 2002; Beraneck and Idoux, 2012), the input synapses that reorganize during vestibular compensation, including sensory ones, might enhance pacemaker properties and concomitantly restrict SK expression in order to 'restart' CVN activity on the lesioned side. Investigations in brainstem slices from guinea pigs at 1 month post-UVD demonstrated that both the spontaneous resting discharge and the discharge evoked by intracellular current injection were increased in the two types of secondary vestibular neurons in ipsilesional CVNs (with a more marked effect in type-B compared to type-A neurons) and that type-B neurons exhibited membrane properties closer to type-A neuron properties (Beraneck et al., 2003).

Cellular and synaptic plasticity initially coincides with several waves of protein kinase-dependent induction of immediate early genes (IEGs), genes that are activated rapidly and transiently in response to a variety of cellular events (for reviews: Beckmann and Wilce, 1997; Minatohara et al., 2016). IEGs induction (e.g., transcription factors fos and zif-268; Lacour and Tighilet, 2010) was identified in CVNs of UVD cats to occur between $3 \mathrm{~h}$ and 7 days after the lesion. Of importance, injecting protein kinase inhibitors in the fourth ventricle of rats dramatically delayed the recovery from UVD-induced motor symptoms (Balaban et al., 1999), suggesting that activating IEGs is necessary to trigger subsequent vestibular compensation processes. Cellular and synaptic plasticity mechanisms are also mirrored by metabolic activity recovery in deafferented CVNs (see Dieringer, 1995), associated with an upregulation of mitochondrial proteins in rats (Paterson et al., 2006). These observations suggest that compensation relies on processes actively engaging several intracellular cascades.

\section{Network Adaptation - Role of Inhibitions}

Besides changes in intrinsic neuronal properties, network reorganization was also reported to occur during the 
compensation process that led to the functional restoration of symmetrical motor activities. As mentioned above, both reactive neurogenesis and gliogenesis were reported to take place soon after UVD. Interestingly, an antimitotic treatment applied during the first 3 weeks post-UVD impairs both neuron and microglia proliferation and drastically delays behavioral recovery (Dutheil et al., 2009), suggesting that generating new cells is a prerequisite for behavioral compensation to occur. In addition, upregulation of proteins involved in axon growth and guidance and in mitochondrial metabolism 1 week after the lesion was reported in UVD rats (Paterson et al., 2006), whereas the early process of activity restoration has been found not to depend on protein synthesis in guinea pigs (Ris et al., 1998). Again, such differences illustrate the variety of mechanisms observed in distinct species. Whereas the role of gliogenesis has not been investigated in this process, neurogenesis, especially GABAergic neuron genesis, could participate in the restoration of bilateral balance between deafferented and intact CVNs (see Tighilet and Chabbert, 2019).

In the adult cat, about $60 \%$ of the new neurons in ipsilesional CVNs survive and display markers of GABAergic INs, which could represent new local and/or commissural INs projecting onto contralateral CVNs (Tighilet et al., 2007). During early stages of vestibular compensation in rats, the responses of secondary vestibular neurons to exogenous GABA application was found to be downregulated in deafferented CVN neurons while they were enhanced on the contralesional side (Yamanaka et al., 2000), and GABA agonists were shown to reduce UVDinduced motor symptoms (Magnusson et al., 2000). In parallel, modifications of expression levels of both GABA receptors and $\mathrm{K}^{+} / \mathrm{Cl}^{-}$co-transporter $\mathrm{KCC} 2$ were also reported in $\mathrm{CVN}$ neurons; however, GABA receptors were bilaterally upregulated, whereas KCC2 was decreased on the ipsilesional side and increased on the contralesional one (Dutheil et al., 2016). KCC2 regulates the chloride transmembrane gradient in neurons and exhibits different levels of expression during development (Schulte et al., 2018). The low expression of KCC2 in early developmental stages does not counteract chloride accumulation in neurons (caused by the other ion cotransporter NKCC1), and GABA receptor activation results in the neuron to be depolarized because of chloride anions exiting the cell. In contrast, KCC2 upregulation during later development strongly decreases the intracellular concentration of chloride ions and so, maintains the chloride gradient in such a way that GABA receptor activation now induces anion entry and neuronal hyperpolarization. Thus, in a UVD context, KCC2 overexpression on the intact side would make contralesional CVN neurons 'more sensitive' to inhibition while KCC2 downregulation in ipsilesional CVN neurons would cause locally the GABAergic (as well as the glycinergic Vibert et al., 2000) neurotransmission to be less inhibitory, or even excitatory (Dutheil et al., 2016). As a consequence, switching GABAergic influence from being inhibitory to being excitatory could represent a homeostatic way to maintain a sufficient excitation level in ipsilesional CVN neurons and further contribute to deafferented neuron survival in the absence of their principal excitatory inputs. Moreover, maintaining excitability of ipsilesional CVN neurons by reducing synaptic inhibition and increasing synaptic excitation may also trigger the changes that are observed in CVN neuron membrane properties, since synaptic inhibition drops before intrinsic properties are modified (Vibert et al., 2000). Interestingly, UVD cats treated with intraventricular injection of brain-derived neurotrophic factor (BDNF) early after the vestibular lesion exhibited increased GABAergic neuron neurogenesis on the ipsilesional side and no KCC2 modification on either side (Dutheil et al., 2016), suggesting that increasing the number of GABAergic neurons would be sufficient to trigger behavioral restoration. This further suggests that KCC2 specific alteration on the two sides may constitute a rapidly acquired but transient state of CVN neurons to restore balance acutely, before inhibition is reequilibrated in ipsilesional CVNs by addition of new functional inhibitory neurons.

Such modifications are thought to impact all inhibitory inputs that converge onto $\mathrm{CVN}$ neurons, i.e., local inhibitory INs, commissural influences and inhibitory projections from the cerebellum (Dieringer and Precht, 1979b; Yamanaka et al., 2000). Long ago, commissural connections were proposed to be primordial in maintaining $\mathrm{CVN}$ bilateral balance, and commissural integrity was demonstrated to be necessary for the restoration of such balance in UVD cats (Precht et al., 1966; Maeda, 1988). In guinea pigs as well, bilateral balance of CVNs is ensured by the bilateral equilibrium of commissural inter-connections (Ris and Godaux, 1998), and restoration of this equilibrium after a UVD is necessary for later behavioral recovery (Olabi et al., 2009). Another argument in favor of a fundamental implication of commissural cross-inhibitions in vestibular compensation was the demonstration in cats that facilitating histamine release enhanced recovery of the affected motor functions (Tighilet et al., 2006). Indeed, histamine released from tuberomammillary cells (in the posterior hypothalamus) onto CVN neurons affects commissural inhibitory pathways and dramatically reduces the response of secondary vestibular neurons to sensory-evoked GABA release (Olabi et al., 2009). It had been shown in UVD cats that the histamine synthesis enzyme was upregulated in the ipsilesional tuberomammillary nucleus during the first week following the vestibular lesion and then slowly returned to control values in a time window consistent with the course of electrophysiological (CVN re-balancing) and behavioral (motor symptoms) recovery (Tighilet et al., 2006). In contrast, it was proposed in terrestrial frogs that vestibular compensation rather involved an increased participation of the excitatory commissural connections from intact to deafferented CVNs (Dieringer and Precht, 1979a; Kunkel and Dieringer, 1994), while inhibitory regulation came principally from the cerebellum (Dieringer and Precht, 1979b).

\section{Cerebellar Changes}

Unilateral vestibular deprivation-induced plasticity in cerebellar nuclei is also likely involved in compensation processes in mammals, although the exact degree of cerebellum implication remains under debate (Smith, 2020). In UVD rats, a NO increase in the cerebellar flocculus had been correlated with fos immunolabeling intensification in ipsilesional and decline in contralesional CVNs, respectively (Kitahara et al., 1997a, 
1999), illustrating the relative overactivity in deafferented CVNs compared to intact ones when cerebellar NO activity rose. Interestingly, blocking NO synthase in the flocculus early after the vestibular lesion resulted in the opposite ratio (Kitahara et al., 1999), due to the UVD-induced asymmetrical activation of CVNs (see above), and caused retardation in motor recovery (Kitahara et al., 1997a). Furthermore, destroying the ipsilesional flocculus prevented any later increase in membrane excitability of deafferented MVN neurons (Kitahara et al., 1997b; Johnston et al., 2002). These results suggest that plasticity in the GABAergic transmission from Purkinje cells plays a significant role in the bilateral re-balancing of CVNs (Figure 4B), likely during the initial phase of vestibular compensation since floccular NO expression has been found to fade afterward during the compensation process (Kitahara et al., 1997a). How such plasticity is triggered in vestibulo-cerebellar networks in response to vestibular asymmetry remains largely unexplored. Nevertheless, the higher expression of acetylcholine described in UVD cat secondary vestibular neurons (Tighilet and Lacour, 1998), which could increasingly activate cholinergic receptors on both cerebellum granule and unipolar brush cells (Jaarsma et al., 1997), might constitute one of the initial cellular events triggering plasticity in cerebellar neurons. Plasticity might result as well from the inactivation of kinases constitutively expressed in Purkinje cells (Barmack et al., 2001) and the return to normal expression levels of glutamate receptor subunit $\delta 2$ after its initial UVD-induced drop (Kitahara et al., 1998). Such a substantial implication of the cerebellum, and that of other higher brain structures such as the hippocampus or inferior olive (Llinás et al., 1975; Wu et al., 2010; for a review, see Darlington and Smith, 2000), suggests that compensation of the permanent loss of vestibular sensory information on one side finally consists of the combined bilateral re-equilibration of CVN activity and development of new motor strategies (Curthoys and Halmagyi, 1999).

\section{Spinal Cord}

Again, almost no dedicated investigations were performed about spinal network alterations and their putative role during postUVD motor recovery processes, and the very few data available come from indirect observations. After vestibular compensation in UVD guinea pigs, for instance, targeted disruption of the ascending spinovestibular fascicule induced the loss of bilateral CVN balance, demonstrating that the integrity of spinal ascending information was necessary to maintain the compensated CVN function (Jensen, 1979b). In addition, in already compensated animals but not in intact controls the same spinal lesion also evoked subsequent postural asymmetries that persisted several days after the surgery (Jensen, 1979a), demonstrating that substantial spinal plasticity occurred that was revealed by the disconnection from brain centers. A recent longitudinal study of gait recovery in UVD humans reported a progressive recovery of step length and ipsilateral stance duration, which was proposed to be the behavioral expression of new motor strategies to compensate for a unilateral vestibular loss (Chae et al., 2021). However, both could also simply reflect some spinal network adaptation, functionally reorganizing in a motor activity-dependent process both the local sensorymotor loops and propriospinal connections to ensure maximum vertical stability of the body. All these observations suggest that during the vestibular compensation process, plasticity certainly also occurs within spinal sensory-motor networks. Indeed, behaviorally relevant sensory-motor plasticity was reported in the spinal cord of chronic UVD terrestrial frogs (Straka and Dieringer, 1995) where neck control recovery initiated before CVN re-balancing and depended on the bilateral enhancement of local cervical reflexes, with stronger effect on the ipsilesional side.

\section{Unilateral Vestibular Deprivation-Induced Developmental Adaptation of Motor Networks}

The specific interruption of semi-circular canal signals on one side early after birth delayed but did not prevent acquisition of motor abilities in rats (Geisler et al., 1997). However, no clear modifications of the temporal organization of locomotion were observed while trunk stability remained non-optimal for a longer time, thus suggesting that retardation might result from a deficit in dynamic coordination between locomotion and posture. Whether such coordination deficits resulted exclusively from the persistent default in descending commands or also from a lack of spinal network adaptation was not investigated. In fact, only few studies have analyzed the impact of a UVD on the subsequent development of spinal neural networks involved in the control of posture and locomotion, and the clearer results come from studies in the aquatic anuran Xenopus laevis (Figure 5).

In the larval Xenopus, as in all vertebrates, a UVD causes a loss of balance between ipsi- and contralesional CVNs; however, contrary to the other animal models, this imbalance is never compensated for and even subsists during metamorphosis to be similarly present in the post-metamorphic frog (Lambert et al., 2008, 2013; Beyeler et al., 2013). Interestingly, UVD effects on posture are identical whether it is performed before (tadpole stage) or after metamorphosis (juvenile stage), with a typical head twist and trunk curvature toward the lesioned side that remains uncorrected, likely because of the lack of ground-related sensory feedback in this purely aquatic animal. Performed at either developmental stage, UVD also similarly evoked locomotor deficits, in the form of a constant rolling behavior toward the lesion side (Beyeler et al., 2013). However, whereas swimming remained impaired in animals lesioned after metamorphosis, those lesioned before metamorphosis recovered near-normal locomotion after metamorphosis completion (Beyeler et al., 2013) whilst brainstem descending commands stayed permanently unbalanced (Lambert et al., 2013). Both in vivo and in vitro analyses of the spinal network responsible for dynamically coordinating posture and propulsion during swimming in post-metamorphic frogs demonstrated dramatic alteration in juveniles that have been lesioned before metamorphosis, compared to control animals or juveniles in which UVD had been performed after metamorphosis (Beyeler et al., 2013). Whereas both control (Beyeler et al., 2008) and juveniles vestibulo-lesioned after metamorphosis 
A

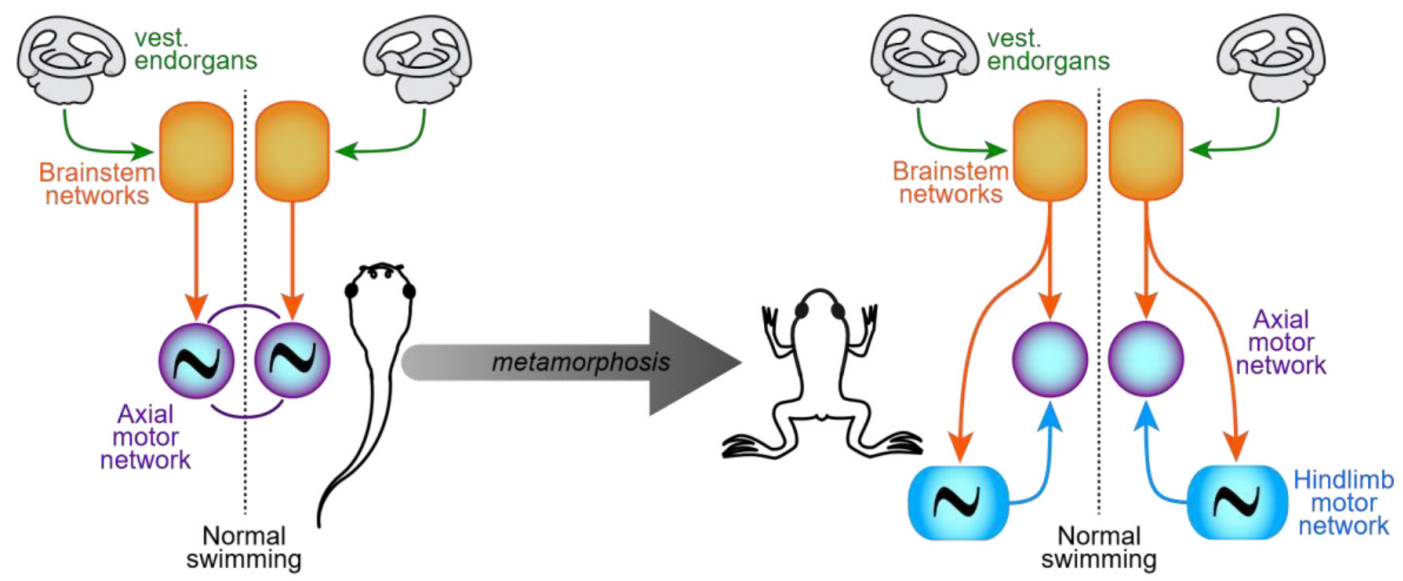

B

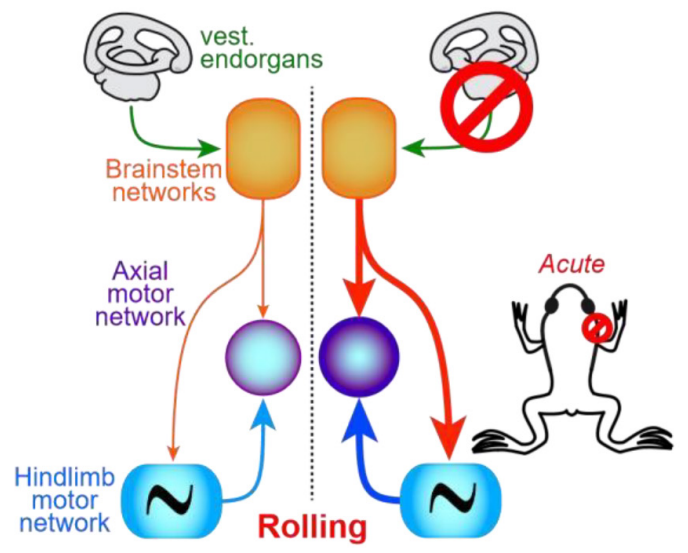

C
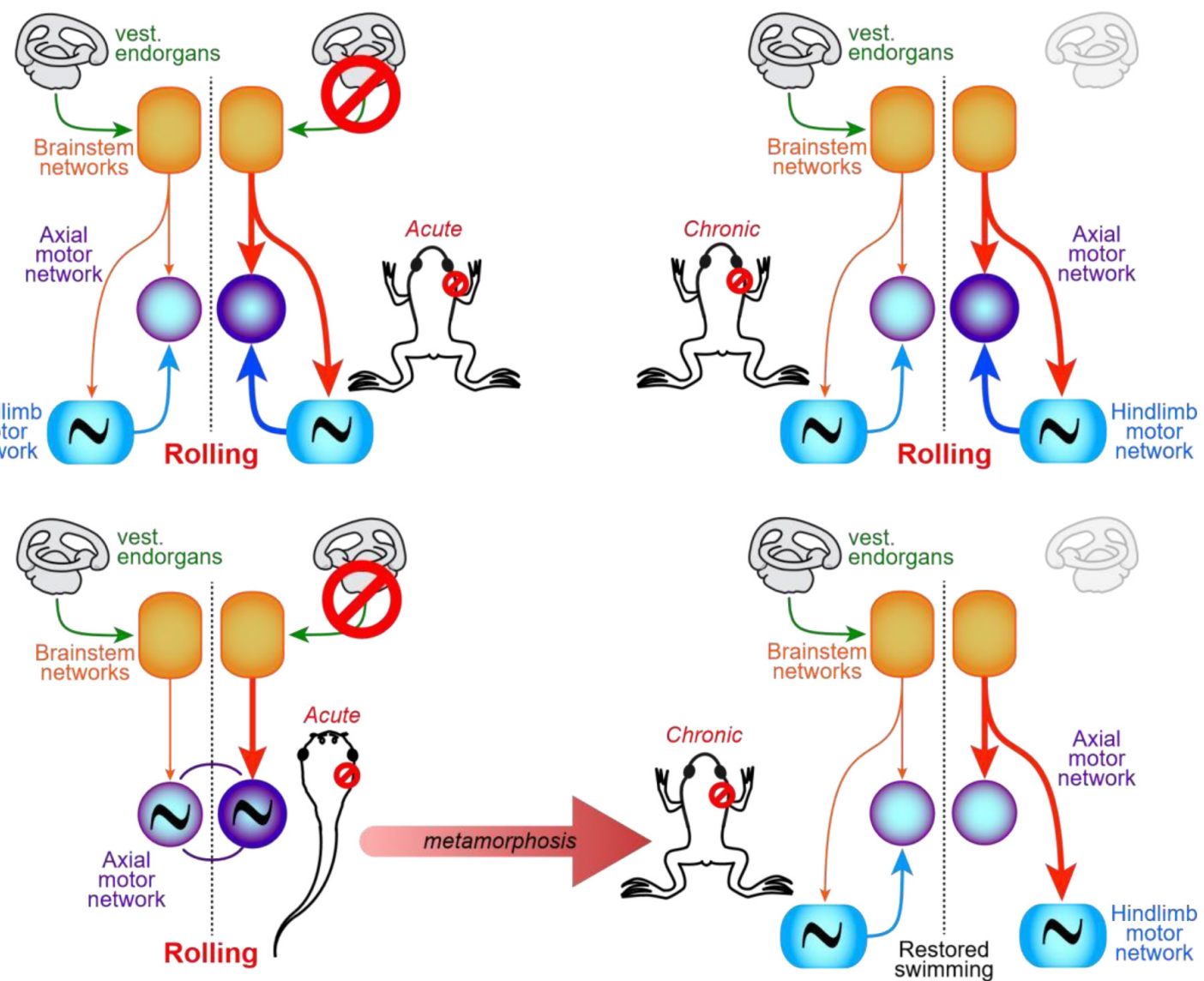

FIGURE 5 | Functional organization of the spinal posturo-locomotor network in the intact and vestibulo-lesioned Xenopus. (A) Schemes illustrating the symmetrical organization of the most basic brainstem/spinal cord sensory-motor network responsible for the control of locomotion and posture in intact pre-metamorphosis tadpole (left) and post-metamorphosis juvenile (right) Xenopus (adapted from Beyeler et al., 2008). (B) Acute (left) and chronic (time interval equivalent to metamorphosis duration; right) effects of a right-side UVD in the juvenile Xenopus. Note that vestibular endorgans/Scarpa ganglion removal generates a net ipsilesional over-excitation of the spinal network, which results in a permanently impaired locomotor behavior (i.e., rolling swimming toward the lesion side; adapted from Beyeler et al., 2013). (C) Acute UVD (left) triggers spinal imbalance and rolling behavior in tadpoles. In contrast, after the animals had metamorphosed (right) normal swimming is restored although bilateral descending commands remain imbalanced. Recovery is allowed by a symmetrical activation of the postural axial network resulting from the construction, during metamorphosis, of an asymmetrical propriospinal posturo-locomotor network (adapted from Beyeler et al., 2013). Thin lines, normal activation; thick lines, hyper-activation; vest., vestibular. 
possessed functionally symmetrical spinal posturo-locomotor networks (Figures 5A,B), juveniles that were lesioned before metamorphosis exhibited an asymmetrical network, characterized by the functional loss on the lesioned side of the lumbo-thoracic coordination subduing axial postural muscles to the appendicular propulsive system (Figure 5C). Biomechanical models demonstrated that this simple alteration was sufficient to counteract the unbalanced brainstem descending commands evoked by the UVD. Indeed, UVD-induced disequilibrium consisted of a relative increase of the commands descending into the ipsilesional side of the cord, notably because of the loss of ipsilesional tangential neurons that normally project into the contralesional hemicord (Lambert et al., 2013). Hence, the 'developmental suppression' of ipsilesional lumbothoracic coordination results, during swimming, in the loss of propriospinal excitation onto postural MNs specifically on the lesion side, while contralateral MNs still receive this ascending excitation. As a result, during swimming the increased descending command on the ipsilesional side is compensated for by the absence of ascending propriospinal excitation, while the reduced descending command on the contralesional side is compensated for by the persistence of (and thus, relative to the other hemicord, increase in) ascending propriospinal excitation originating from the lumbar CPG. Altogether, these two opposite asymmetries lead to re-balancing activity in the spinal postural system during locomotion and allow normal (non-rolling) swimming in juveniles that underwent a UVD before metamorphosis.

Whether such spinal reorganizations are specific to Xenopus metamorphosis or occur similarly in other vertebrate species remains to be determined. Although very few investigations have been made in this direction, several indirect results tend to indicate that UVD-triggered spinal network adaptations may constitute a general feature in a majority of vertebrates. Hence, adult UVD rats that display severe postural defects at rest and dramatically unstable locomotion at low speed of walking, exhibit a more stable body balance with increased locomotor velocity (Rastoldo et al., 2020). Similarly, a running UVD dog shows less deviation from the normal path and less imbalance than during walking (Brandt et al., 1999). Interestingly, the exact same observations were made in patients with acute vestibulopathy in which walking strides were more regular and body balance more accurate at high velocity than at low speed (Brandt et al., 1999; Schniepp et al., 2012; reviewed in Akay and Murray, 2021). Two explanations could account for such a 'speed-dependence' of posture and gait in UVD subjects. First, this could result from decreasing the weight of vestibulospinal control onto spinal networks during high velocity locomotion as proposed by Akay and Murray (2021). Indeed, a study in healthy human subjects showed that gait deviation induced by a vestibular galvanic stimulation was reduced by half during running compared to walking, suggesting that higher locomotor speed exerted stronger inhibitory control on descending vestibulospinal commands (Jahn et al., 2000). In this study, however, galvanic stimulation mimicked sudden shifts of head position while locomotion was already ongoing, generating disrupting vestibular signals thus superimposed on still symmetrical tonic descending influences from gravity detectors. Of course, it is totally different in subjects with acute vestibular imbalance, where the basal tonic influence is no more symmetrical. An alternative explanation would arise from the possibility that, as demonstrated in juvenile Xenopus (Beyeler et al., 2008), the spinal posturo-locomotor network is intrinsically able to organize postural controls that are dynamically adapted to the ongoing propulsive motor program. In this context, locomotion and dynamic control of posture would be principally based on highly automated programs organized by spinal networks coordinated through propriospinal interconnections and under control of both tonic and dynamic supraspinal modulation (e.g., OlechowskiBessaguet et al., 2020). The relative weight of propriospinal coordination vs. descending commands would then determine how the dynamic control of posture would be achieved (Beyeler et al., 2013): stronger is the spinally generated motor command, lower is the relative weight of dynamic descending inputs. Whether such balance is purely orchestrated at the spinal synaptic level or rather/additionally involves direct modulation of sensory inputs at the supraspinal level (Le Ray et al., 2010; Chagnaud et al., 2015; Straka et al., 2018) still has to be determined. Thus, running may rely much less on dynamic descending inputs than slow walking does. Yet, after UVD this would require precise alterations of the spinal posturo-locomotor network taking into account the persistent disequilibrium in tonic descending influences. However, contrary to what was described in the metamorphosing Xenopus where propriospinal adaptation result from developmental processes, it is likely that such alterations in mammals would rather involve plastic adaptations closer to those consecutive to a unilateral SCI. The existence of such UVDtriggered spinal reorganization, whether it is developmental or adaptive, confronts the classical conclusions about UVD effects on the control of posture (e.g., Vidal et al., 1993) which were drawn from studies restricted to the control of the so-called 'static' posture.

\section{CONCLUSION}

In pluricellular organisms, the development of symmetry relies on both animal genetics and inter-cell communication (Allard and Tabin, 2009; Moubayidin and Østergaard, 2015), and symmetries appear to be the most appropriate patterns in the evolution of animal body arrangement (Holló, 2015). Spatial coordination between limb muscles is organized symmetrically from pelvis to ankle, which ensures best and less energy consuming locomotion (Saunders et al., 1953), and patients with developmental coordination disorders present asymmetrical gait and impaired locomotor efficacy compared to neurotypical subjects (Wilmut et al., 2017). Thus, due to the bilaterally symmetrical arrangement of their biomechanical apparatus, animals require a similar symmetry in the structure of their basic sensory-motor circuits, from development to adulthood, to achieve accurate locomotor and postural controls (Farel and McIlwain, 2000; Holló, 2015).

Here, we have reviewed several (non-exhaustive) examples of behavioral consequences of accidental breaks in fundamental 
symmetry of the sensory-motor CNS throughout the vertebrate kingdom, as well as plasticity that is elicited to face the motor deficits generated by such symmetry failures. We have seen that sensory-motor networks can cope quite remarkably well with the information remaining in injured and incapacitated motor or sensory nervous structures. As a result, plasticity mechanisms distributed throughout the CNS orchestrate the reestablishment of bilateral neural equilibrium, i.e., the best possible functional symmetry within spared neuronal networks and pathways, whether injury was of central or sensory origin. Such a generalization of homeostatic plasticity leads to the conclusion that symmetry in the motor CNS is a functional necessity and not merely an 'experimentally impossible to verify but plausible just-so' of evolution (see Cooke, 2004). Indeed, all reactions at cellular, synaptic or network level initiated in response to unilateral neural injuries tend to restore the lost functional symmetry in the sensory-motor CNS. In addition, adaptations are not restrained but involve the sensory-motor CNS as a whole, and behavioral recovery depends on the interplay between all neural actors. Nevertheless, every single elements comparably possesses the ability to adapt its operation in response to an accidental loss of neural symmetry, as observed for instance in cats where, after complete transection, spinal circuitry retains the ability to adjust to ulterior cutaneous denervation (Bouyer and Rossignol, 2003).

Finally, what does determine symmetry in the sensorymotor CNS, during development and afterward? It is commonly admitted that body symmetry, as well as natural symmetry breaks, are strictly encoded, the genome being capable of selecting the adequate scheme according to the animal's behavioral requirements (Holló, 2015). Yet, it is not clear what kind of symmetry is encoded when we consider posturo-locomotor functions. According to the general rule enacted in biology (Holló, 2015; Moubayidin and Østergaard, 2015), one may answer that genes encode the structural

\section{REFERENCES}

Ahuja, C. S., Wilson, J. R., Nori, S., Kotter, M. R. N., Druschel, C., Curt, A., et al. (2017). Traumatic spinal cord injury. Nat. Rev. Dis. Primer 3:17018. doi: $10.1038 /$ nrdp. 2017.18

Akay, T., and Murray, A. J. (2021). Relative contribution of proprioceptive and vestibular sensory systems to locomotion: opportunities for discovery in the age of molecular science. Int. J. Mol. Sci. 22:1467. doi: 10.3390/ijms22031467

Alizadeh, A., Dyck, S. M., and Karimi-Abdolrezaee, S. (2019). Traumatic spinal cord injury: an overview of pathophysiology, models and acute injury mechanisms. Front. Neurol. 10:282. doi: 10.3389/fneur.2019.00282

Allard, P., and Tabin, C. J. (2009). Achieving bilateral symmetry during vertebrate limb development. Semin. Cell Dev. Biol. 20, 479-484. doi: 10.1016/j.semcdb. 2008.10.011

Alvarez, F. J., Bullinger, K. L., Titus, H. E., Nardelli, P., and Cope, T. C. (2010). Permanent reorganization of Ia afferent synapses on motoneurons after peripheral nerve injuries: monosynaptic stretch reflexes after nerve injuries. Ann. N. Y. Acad. Sci. 1198, 231-241. doi: 10.1111/j.1749-6632.2010.05459.x

Andrew, R. J. (2009). Origins of asymmetry in the CNS. Semin. Cell Dev. Biol. 20, 485-490. doi: 10.1016/j.semcdb.2008.11.001

Azzena, G. B. (1969). Role of the spinal cord in compensating the effects of hemilabyrinthectomy. Arch. Ital. Biol. 107, 43-53.

Bagnall, M. W., and McLean, D. L. (2014). Modular organization of axial microcircuits in zebrafish. Science 343, 197-200. doi: 10.1126/science.1245629 symmetry of the sensory-motor CNS. However, based on studies reviewed above illustrating the sensory-motor CNS extraordinary capacity to adapt and change its organization to restore the most accurate function after an accidental loss of central or sensory symmetry, we propose that function (here, posturo-locomotor control) rather than CNS strict anatomical arrangement may be the fundamental target of networks developmental assembly. Especially, experiments performed in metamorphosing Xenopus (Beyeler et al., 2013) strongly support this view since altering symmetry in vestibular sensory inputs during posturo-locomotor network metamorphic construction triggered the establishment of an asymmetrical spinal motor network able to ensure an appropriate function in a still sensory-deprived, postmetamorphic animal.

\section{AUTHOR CONTRIBUTIONS}

DLR and MG wrote the manuscript. Both authors contributed to the article and approved the submitted version.

\section{FUNDING}

This study was supported by the Centre National de la Recherche Scientifique and the Centre National des Etudes Spatiales.

\section{ACKNOWLEDGMENTS}

The authors are grateful to François M. Lambert and Grégory Barrière, for their critical reading and their valuable comments on this manuscript. The authors also thank F.M. Lambert for his priceless help in illustrating this review.

Bagnall, M. W., and Schoppik, D. (2018). Development of vestibular behaviors in zebrafish. Curr. Opin. Neurobiol. 53, 83-89. doi: 10.1016/j.conb.2018.06.004

Balaban, C. D., Freilino, M., and Romero, G. G. (1999). Protein kinase C inhibition blocks the early appearance of vestibular compensation. Brain Res. 845, 97-101. doi: 10.1016/S0006-8993(99)01958-7

Ballion, B., Morin, D., and Viala, D. (2001). Forelimb locomotor generators and quadrupedal locomotion in the neonatal rat: quadrupedal locomotion in the neonatal rat. Eur. J. Neurosci. 14, 1727-1738. doi: 10.1046/j.0953-816x.2001. 01794.x

Bareyre, F. M., Haudenschild, B., and Schwab, M. E. (2002). Long-lasting sprouting and gene expression changes induced by the monoclonal antibody IN-1 in the adult spinal cord. J. Neurosci. 22, 7097-7110. doi: 10.1523/JNEUROSCI.22-1607097.2002

Bareyre, F. M., Kerschensteiner, M., Raineteau, O., Mettenleiter, T. C., Weinmann, O., and Schwab, M. E. (2004). The injured spinal cord spontaneously forms a new intraspinal circuit in adult rats. Nat. Neurosci. 7, 269-277. doi: 10.1038/ nn1195

Barmack, N., Qian, Z.-Y., Kim, H., and Yoshimura, J. (2001). Activity-dependent distribution of protein kinase $\mathrm{C}-\delta$ within rat cerebellar Purkinje cells following unilateral labyrinthectomy. Exp. Brain Res. 141, 6-20. doi: 10.1007/ s002210100855

Barrière, G., Frigon, A., Leblond, H., Provencher, J., and Rossignol, S. (2010). Dual spinal lesion paradigm in the cat: evolution of the kinematic locomotor pattern. J. Neurophysiol. 104, 1119-1133. doi: 10.1152/jn.00255.2010 
Barrière, G., Leblond, H., Provencher, J., and Rossignol, S. (2008). Prominent role of the spinal central pattern generator in the recovery of locomotion after partial spinal cord injuries. J. Neurosci. 28, 3976-3987. doi: 10.1523/JNEUROSCI. 5692-07.2008

Bazley, F. A., Hu, C., Maybhate, A., Pourmorteza, A., Pashai, N., Thakor, N. V., et al. (2012). Electrophysiological evaluation of sensory and motor pathways after incomplete unilateral spinal cord contusion: laboratory investigation. J. Neurosurg. Spine 16, 414-423. doi: 10.3171/2012.1.SPINE 11684

Bazley, F. A., Maybhate, A., Tan, C. S., Thakor, N. V., Kerr, C., and All, A. H. (2014). Enhancement of bilateral cortical somatosensory evoked potentials to intact forelimb stimulation following thoracic contusion spinal cord injury in rats. IEEE Trans. Neural Syst. Rehabil. Eng. 22, 953-964. doi: 10.1109/TNSRE. 2014.2319313

Beckmann, A. M., and Wilce, P. A. (1997). Egr transcription factors in the nervous system. Neurochem. Int. 31, 477-510. doi: 10.1016/s0197-0186(96)00136-2

Benbir, G., Kara, S., Yalcinkaya, B. C., Karlıkaya, G., Tuysuz, B., Kocer, N., et al. (2011). Unilateral cerebellar hypoplasia with different clinical features. Cerebellum 10, 49-60. doi: 10.1007/s12311-010-0225-2

Beraneck, M., Hachemaoui, M., Idoux, E., Ris, L., Uno, A., Godaux, E., et al. (2003). Long-term plasticity of ipsilesional medial vestibular nucleus neurons after unilateral labyrinthectomy. J. Neurophysiol. 90, 184-203. doi: 10.1152/jn. 01140.2002

Beraneck, M., and Idoux, E. (2012). Reconsidering the role of neuronal intrinsic properties and neuromodulation in vestibular homeostasis. Front. Neurol. 3:25. doi: $10.3389 /$ fneur.2012.00025

Berg, E. M., Björnfors, E. R., Pallucchi, I., Picton, L. D., and El Manira, A. (2018). Principles governing locomotion in vertebrates: lessons from zebrafish. Front. Neural Circuits 12:73. doi: 10.3389/fncir.2018.00073

Berkowitz, A., Roberts, A., and Soffe, S. R. (2010). Roles for multifunctional and specialized spinal interneurons during motor pattern generation in tadpoles, Zebrafish larvae, and turtles. Front. Behav. Neurosci. 4:36. doi: 10.3389/fnbeh. 2010.00036

Beyeler, A., Métais, C., Combes, D., Simmers, J., and Le Ray, D. (2008). Metamorphosis-induced changes in the coupling of spinal thoraco-lumbar motor outputs during swimming in Xenopus laevis. J. Neurophysiol. 100, 13721383. doi: $10.1152 /$ jn. 00023.2008

Beyeler, A., Rao, G., Ladepeche, L., Jacques, A., Simmers, J., and Le Ray, D. (2013). Vestibular lesion-induced developmental plasticity in spinal locomotor networks during Xenopus laevis metamorphosis. PLoS One 8:e71013. doi: 10. 1371/journal.pone.0071013

Blum, M., and Ott, T. (2018). Animal left-right asymmetry. Curr. Biol. 28, R301R304. doi: 10.1016/j.cub.2018.02.073

Boulenguez, P., Liabeuf, S., Bos, R., Bras, H., Jean-Xavier, C., Brocard, C., et al. (2010). Down-regulation of the potassium-chloride cotransporter KCC2 contributes to spasticity after spinal cord injury. Nat. Med. 16, 302-307. doi: $10.1038 / \mathrm{nm} .2107$

Bouyer, L. J. G., and Rossignol, S. (2003). Contribution of cutaneous inputs from the hindpaw to the control of locomotion. II. Spinal cats. J. Neurophysiol. 90, 3640-3653. doi: 10.1152/jn.00497.2003

Bradley, P. M., Denecke, C. K., Aljovic, A., Schmalz, A., Kerschensteiner, M., and Bareyre, F. M. (2019). Corticospinal circuit remodeling after central nervous system injury is dependent on neuronal activity. J. Exp. Med. 216, 2503-2514. doi: $10.1084 /$ jem.20181406

Bramati, I. E., Rodrigues, E. C., Simões, E. L., Melo, B., Höfle, S., Moll, J., et al. (2019). Lower limb amputees undergo long-distance plasticity in sensorimotor functional connectivity. Sci. Rep. 9:2518. doi: 10.1038/s41598-019-39696-Z

Brandt, T., Strupp, M., and Benson, J. (1999). You are better off running than walking with acute vestibulopathy. Lancet 354:746. doi: 10.1016/S01406736(99)03179-7

Brown, A., and Martinez, M. (2019). From cortex to cord: motor circuit plasticity after spinal cord injury. Neural Regen. Res. 14:2054. doi: 10.4103/1673-5374. 262572

Brus-Ramer, M., Carmel, J. B., Chakrabarty, S., and Martin, J. H. (2007). Electrical stimulation of spared corticospinal axons augments connections with ipsilateral spinal motor circuits after injury. J. Neurosci. 27, 13793-13801. doi: 10.1523/ JNEUROSCI.3489-07.2007
Buonomano, D. V., and Merzenich, M. M. (1998). CORTICAL PLASTICITY: from synapses to maps. Annu. Rev. Neurosci. 21, 149-186. doi: 10.1146/annurev. neuro.21.1.149

Cacciola, A., Milardi, D., Basile, G. A., Bertino, S., Calamuneri, A., Chillemi, G., et al. (2019). The cortico-rubral and cerebello-rubral pathways are topographically organized within the human red nucleus. Sci. Rep. 9:12117. doi: 10.1038/s41598-019-48164-7

Calton, J. L., Philbrick, K., and Mcclellan, A. D. (1998). Anatomical regeneration and behavioral recovery following crush injury of the trigeminal root in lamprey. J. Comp. Neurol. 396, 322-337.

Cangiano, L., and Grillner, S. (2005). Mechanisms of rhythm generation in a spinal locomotor network deprived of crossed connections: the lamprey hemicord. J. Neurosci. 25, 923-935. doi: 10.1523/JNEUROSCI.2301-04.2005

Carcaud, J., França de Barros, F., Idoux, E., Eugène, D., Reveret, L., Moore, L. E., et al. (2017). Long-lasting visuo-vestibular mismatch in freely-behaving mice reduces the vestibulo-ocular reflex and leads to neural changes in the direct vestibular pathway. eneuro 4: ENEURO.0290-16.2017. doi: 10.1523/ENEURO. 0290-16.2017

Carpenter, M. B., Stein, B. M., and Peter, P. (1972). Primary vestibulocerebellar fibers in the monkey: distribution of fibers arising from distinctive cell groups of the vestibular ganglia. Am. J. Anat. 135, 221-249. doi: 10.1002/aja.1001350209

Carrier, L., Brustein, E., and Rossignol, S. (1997). Locomotion of the hindlimbs after neurectomy of ankle flexors in intact and spinal cats: model for the study of locomotor plasticity. J. Neurophysiol. 77, 1979-1993. doi: 10.1152/jn.1997.77. 4.1979

Cass, S. P., and Goshgarian, H. G. (1990). Increased glial fibrillary acidic protein immunoreactivity in astrocytes within the lateral vestibular nucleus of the cat following labyrinthectomy and vestibular neurectomy. Ann. Otol. Rhinol. Laryngol. 99, 221-227. doi: 10.1177/000348949009900312

Cassel, R., Wiener-Vacher, S., El Ahmadi, A., Tighilet, B., and Chabbert, C. (2018). Reduced balance restoration capacities following unilateral vestibular insult in elderly mice. Front. Neurol. 9:462. doi: 10.3389/fneur.2018.00462

Cazalets, J., Borde, M., and Clarac, F. (1995). Localization and organization of the central pattern generator for hindlimb locomotion in newborn rat. J. Neurosci. 15:4943. doi: 10.1523/JNEUROSCI.15-07-04943.1995

Chae, S., Song, J.-J., and Kim, W.-S. (2021). Change of gait after unilateral vestibular neuritis: a prospective longitudinal observation study. Sci. Rep. 11:21579. doi: 10.1038/s41598-021-00665-0

Chagnaud, B. P., Banchi, R., Simmers, J., and Straka, H. (2015). Spinal corollary discharge modulates motion sensing during vertebrate locomotion. Nat. Commun. 6:7982. doi: 10.1038/ncomms8982

Chen, Y., Chen, X. Y., Jakeman, L. B., Chen, L., Stokes, B. T., and Wolpaw, J. R. (2006). Operant conditioning of H-reflex can correct a locomotor abnormality after spinal cord injury in rats. J. Neurosci. 26, 12537-12543. doi: 10.1523/ JNEUROSCI.2198-06.2006

Combes, D., Le Ray, D., Lambert, F. M., Simmers, J., and Straka, H. (2008). An intrinsic feed-forward mechanism for vertebrate gaze stabilization. Curr. Biol. 18, R241-R243. doi: 10.1016/j.cub.2008.02.018

Conboy, V., Edwards, C., Ainsworth, R., Natusch, D., Burcham, C., Danisment, B., et al. (2021). Chronic musculoskeletal impairment is associated with alterations in brain regions responsible for the production and perception of movement. J. Physiol. 599, 2255-2272. doi: 10.1113/JP281273

Concha, M. L., and Wilson, S. W. (2001). Asymmetry in the epithalamus of vertebrates. J. Anat. 199, 63-84. doi: 10.1046/j.1469-7580.2001.19910063.x

Cooke, J. (2004). Developmental mechanism and evolutionary origin of vertebrate left/right asymmetries. Biol. Rev. 79, 377-407. doi: 10.1017/S1464793103006298

Cooke, R. M., and Parker, D. (2009). Locomotor recovery after spinal cord lesions in the lamprey is associated with functional and ultrastructural changes below lesion sites. J. Neurotrauma 26, 597-612. doi: 10.1089/neu.2008.0660

Côté, M.-P., Azzam, G. A., Lemay, M. A., Zhukeareva, V., and Houlé, J. D. (2011). Activity-dependent increase in neurotrophic factors is associated with an enhanced modulation of spinal reflexes after spinal cord injury. J. Neurotrauma 28, 299-309. doi: 10.1089/neu.2010.1594

Côté, M.-P., Detloff, M. R., Wade, R. E., Lemay, M. A., and Houlé, J. D. (2012). Plasticity in ascending long propriospinal and descending supraspinal pathways in chronic cervical spinal cord injured rats. Front. Physiol. 3:330. doi: 10.3389/ fphys.2012.00330 
Côté, M.-P., Murray, L. M., and Knikou, M. (2018). Spinal control of locomotion: individual neurons, their circuits and functions. Front. Physiol. 9:784. doi: 10. 3389/fphys.2018.00784

Cullen, K. E. (2016). Physiology of central pathways. Handb. Clin. Neurol. 137, 17-40. doi: 10.1016/B978-0-444-63437-5.00002-9

Cullen, K. E. (2019). Vestibular processing during natural self-motion: implications for perception and action. Nat. Rev. Neurosci. 20, 346-363. doi: 10.1038/s41583019-0153-1

Curthoys, I. S., and Halmagyi, G. M. (1999). Vestibular compensation. Adv. Otorhinolaryngol. 55, 82-110. doi: 10.1159/000059059

Dambreville, C., Labarre, A., Thibaudier, Y., Hurteau, M.-F., and Frigon, A. (2015). The spinal control of locomotion and step-to-step variability in leftright symmetry from slow to moderate speeds. J. Neurophysiol. 114, 1119-1128. doi: $10.1152 /$ jn.00419.2015

Darian-Smith, C., Lilak, A., and Alarcón, C. (2013). Corticospinal sprouting occurs selectively following dorsal rhizotomy in the macaque monkey. J. Comp. Neurol. 521, 2359-2372. doi: 10.1002/cne.23289

Darian-Smith, C., Lilak, A., Garner, J., and Irvine, K.-A. (2014). Corticospinal sprouting differs according to spinal injury location and cortical origin in macaque monkeys. J. Neurosci. 34, 12267-12279. doi: 10.1523/JNEUROSCI. 1593-14.2014

Darlington, C. L., Dutia, M. B., and Smith, P. F. (2002). The contribution of the intrinsic excitability of vestibular nucleus neurons to recovery from vestibular damage: recovery from vestibular damage: role of vestibular nucleus. Eur. J. Neurosci. 15, 1719-1727. doi: 10.1046/j.1460-9568.2002.02024.x

Darlington, C. L., and Smith, P. F. (2000). Molecular mechanisms of recovery from vestibular damage in mammals: recent advances. Prog. Neurobiol. 62, 313-325. doi: 10.1016/S0301-0082(00)00002-2

Darlington, C. L., Smith, P. F., and Hubbard, J. I. (1989). Neuronal activity in the guinea pig medial vestibular nucleus in vitro following chronic unilateral labyrinthectomy. Neurosci. Lett. 105, 143-148. doi: 10.1016/0304-3940(89) 90026-8

de Leon, R. D., Tamaki, H., Hodgson, J. A., Roy, R. R., and Edgerton, V. R. (1999). Hindlimb locomotor and postural training modulates glycinergic inhibition in the spinal cord of the adult spinal cat. J. Neurophysiol. 82, 359-369. doi: 10.1152/jn.1999.82.1.359

de Sèze, M., Falgairolle, M., Viel, S., Assaiante, C., and Cazalets, J.-R. (2008). Sequential activation of axial muscles during different forms of rhythmic behavior in man. Exp. Brain Res. 185, 237-247. doi: 10.1007/s00221-007-1146-2

De Waele, C., Torres, A. C., Josset, P., and Vidal, P. P. (1996). Evidence for reactive astrocytes in rat vestibular and cochlear nuclei following unilateral inner ear lesion. Eur. J. Neurosci. 8, 2006-2018. doi: 10.1111/j.1460-9568.1996.tb013 44.x

D'Elia, K. P., and Dasen, J. S. (2018). Development, functional organization, and evolution of vertebrate axial motor circuits. Neural Dev. 13:10. doi: 10.1186/ s13064-018-0108-7

Deliagina, T. G. (1997). Vestibular compensation in lampreys: impairment and recovery of equilibrium control during locomotion. J. Exp. Biol. 200, 14591471. doi: 10.1242/jeb.200.10.1459

Deliagina, T. G., Beloozerova, I. N., Orlovsky, G. N., and Zelenin, P. V. (2014). Contribution of supraspinal systems to generation of automatic postural responses. Front. Integr. Neurosci. 8:76. doi: 10.3389/fnint.2014.00076

Deliagina, T. G., Orlovsky, G. N., Grillner, S., and Wallén, P. (1992). Vestibular control of swimming in lamprey. II. Characteristics of spatial sensitivity of reticulospinal neurons. Exp. Brain Res. 90, 489-498. doi: 10.1007/BF0023 0931

Dieringer, N. (1995). "Vestibular compensation": neural plasticity and its relations tp functional recovery after labyrinthine lesions in frogs and other vertebrates. Prog. Neurobiol. 46, 97-129. doi: 10.1016/0301-0082(94)00063-n

Dieringer, N., Kunzle, H., and Precht, W. (1984). Increased projection of ascending dorsal root fibers to vestibular nuclei after hemilabyrinthectomy in the frog. Exp. Brain Res. 55, 574-578. doi: 10.1007/BF00235289

Dieringer, N., and Precht, W. (1979b). Mechanisms of compensation for vestibular deficits in the frog. II. Modification of the inhibitory Pathways. Exp. Brain Res. 36, 329-357. doi: 10.1007/BF00238915

Dieringer, N., and Precht, W. (1979a). Mechanisms of compensation for vestibular deficits in the frog. I. Modification of the excitatory commissural system. Exp. Brain Res. 36, 311-328. doi: 10.1007/BF00238914
Dietrich, H., Heidger, F., Schniepp, R., MacNeilage, P. R., Glasauer, S., and Wuehr, M. (2020). Head motion predictability explains activity-dependent suppression of vestibular balance control. Sci. Rep. 10:668. doi: 10.1038/s41598-019-57400-z

Dietrich, H., and Wuehr, M. (2019). Strategies for gaze stabilization critically depend on locomotor speed. Neuroscience 408, 418-429. doi: 10.1016/j. neuroscience.2019.01.025

Dietz, V., and Fouad, K. (2014). Restoration of sensorimotor functions after spinal cord injury. Brain 137, 654-667. doi: 10.1093/brain/awt262

Dutheil, S., Brezun, J. M., Leonard, J., Lacour, M., and Tighilet, B. (2009). Neurogenesis and astrogenesis contribution to recovery of vestibular functions in the adult cat following unilateral vestibular neurectomy: cellular and behavioral evidence. Neuroscience 164, 1444-1456. doi: 10.1016/j.neuroscience. 2009.09.048

Dutheil, S., Watabe, I., Sadlaoud, K., Tonetto, A., and Tighilet, B. (2016). BDNF signaling promotes vestibular compensation by increasing neurogenesis and remodeling the expression of potassium-chloride cotransporter KCC2 and GABA a receptor in the vestibular nuclei. J. Neurosci. 36, 6199-6212. doi: 10.1523/JNEUROSCI.0945-16.2016

Edgerton, V. R., de Leon, R. D., Harkema, S. J., Hodgson, J. A., London, N., Reinkensmeyer, D. J., et al. (2001). Retraining the injured spinal cord. J. Physiol. 533, 15-22. doi: 10.1111/j.1469-7793.2001.0015b.x

El-Daher, F., and Becker, C. G. (2020). Neural circuit reorganisation after spinal cord injury in zebrafish. Curr. Opin. Genet. Dev. 64, 44-51. doi: 10.1016/j.gde. 2020.05.017

Engmann, A. K., Bizzozzero, F., Schneider, M. P., Pfyffer, D., Imobersteg, S., Schneider, R., et al. (2020). The gigantocellular reticular nucleus plays a significant role in locomotor recovery after incomplete spinal cord injury. J. Neurosci. 40, 8292-8305. doi: 10.1523/JNEUROSCI.0474-20.2020

Facchini, J., Rastoldo, G., Xerri, C., Péricat, D., El Ahmadi, A., Tighilet, B., et al. (2021). Unilateral vestibular neurectomy induces a remodeling of somatosensory cortical maps. Prog. Neurobiol. 205:102119. doi: 10.1016/j. pneurobio.2021.102119

Falgairolle, M., and Cazalets, J.-R. (2007). Metachronal coupling between spinal neuronal networks during locomotor activity in newborn rat: synchronization between neuronal networks. J. Physiol. 580, 87-102. doi: 10.1113/jphysiol.2006. 115709

Farel, P. B., and McIlwain, D. L. (2000). Neuron addition and enlargement in juvenile and adult animals. Brain Res. Bull. 53, 537-546. doi: 10.1016/S03619230(00)00387-7

Fouad, K., Metz, G. A. S., Merkler, D., Dietz, V., and Schwab, M. E. (2000). Treadmill training in incomplete spinal cord injured rats. Behav. Brain Res. 115, 107-113. doi: 10.1016/S0166-4328(00)00244-8

Frigon, A., Barrière, G., Leblond, H., and Rossignol, S. (2009). Asymmetric changes in cutaneous reflexes after a partial spinal lesion and retention following spinalization during locomotion in the cat. J. Neurophysiol. 102, 2667-2680. doi: 10.1152/jn.00572.2009

Fritzsch, B., Kopecky, B. J., and Duncan, J. S. (2014). “Chapter 12 - Development of the mammalian 'vestibular' system: evolution of form to detect angular and gravity acceleration," in Development of Auditory and Vestibular Systems, eds R. Romand and I. Varela-Nieto (San Diego, CA: Academic Press), 339-367. doi: 10.1016/b978-0-12-408088-1.00012-9

Gaboyard-Niay, S., Travo, C., Saleur, A., Broussy, A., Brugeaud, A., and Chabbert, C. (2016). Correlation between afferent rearrangements and behavioral deficits after local excitotoxic insult in the mammalian vestibule: an animal model of vertigo symptoms? Dis. Model. Mech. 9, 1181-1192. doi: 10.1242/dmm.024521

Galea, M. P., Hammar, I., Nilsson, E., and Jankowska, E. (2010). Bilateral postsynaptic actions of pyramidal tract and reticulospinal neurons on feline erector spinae motoneurons. J. Neurosci. 30, 858-869. doi: 10.1523/ JNEUROSCI.4859-09.2010

García-Alías, G., Valero-Cabré, A., López-Vales, R., Forés, J., Verdú, E., and Navarro, X. (2006). Differential motor and electrophysiological outcome in rats with mid-thoracic or high lumbar incomplete spinal cord injuries. Brain Res. 1108, 195-204. doi: 10.1016/j.brainres.2006.06.029

Garcia-Ramirez, D. L., Ha, N. T., Bibu, S., Stachowski, N. J., and Dougherty, K. J. (2021). Spinal cord injury alters spinal Shox2 interneurons by enhancing excitatory synaptic input and serotonergic modulation while maintaining intrinsic properties in mouse. J. Neurosci. 41, 5833-5848. doi: 10.1523/ JNEUROSCI.1576-20.2021 
Gazula, V.-R., Roberts, M., Luzzio, C., Jawad, A. F., and Kalb, R. G. (2004). Effects of limb exercise after spinal cord injury on motor neuron dendrite structure. J. Comp. Neurol. 476, 130-145. doi: 10.1002/cne.20204

Geisler, H. C., van der Fits, I. B. M., and Gramsbergen, A. (1997). The effects of early vestibular deprivation on the motor development in the rat. Behav. Brain Res. 86, 89-96. doi: 10.1016/S0166-4328(96)02246-2

Gervasio, S., Kersting, U. G., Farina, D., and Mrachacz-Kersting, N. (2015). The effect of crossed reflex responses on dynamic stability during locomotion. J. Neurophysiol. 114, 1034-1040. doi: 10.1152/jn.00178.2015

Ghosh, A., Sydekum, E., Haiss, F., Peduzzi, S., Zorner, B., Schneider, R., et al. (2009). Functional and anatomical reorganization of the sensory-motor cortex after incomplete spinal cord injury in adult rats. J. Neurosci. 29, 12210-12219. doi: 10.1523/JNEUROSCI.1828-09.2009

Giszter, S. F., Kargo, W. J., Davies, M., and Shibayama, M. (1998). Fetal transplants rescue axial muscle representations in $\mathrm{M} 1$ cortex of neonatally transected rats that develop weight support. J. Neurophysiol. 80, 3021-3030. doi: 10.1152/jn. 1998.80.6.3021

Gliddon, C., Darlington, C., and Smith, P. (2005). GABAergic systems in the vestibular nucleus and their contribution to vestibular compensation. Prog. Neurobiol. 75, 53-81. doi: 10.1016/j.pneurobio.2004.11.001

Goldberger, M. E. (1977). Locomotor recovery after unilateral hindlimb deafferentation in cats. Brain Res. 123, 59-74. doi: 10.1016/0006-8993(77) 90643-6

Goldberger, M. E. (1988). Partial and complete deafferentation of cat hindlimb: the contribution of behavioral substitution to recovery of motor function. Exp. Brain Res. 73, 343-353. doi: 10.1007/BF00248226

Goldshmit, Y., Lythgo, N., Galea, M. P., and Turnley, A. M. (2008). Treadmill training after spinal cord hemisection in mice promotes axonal sprouting and synapse formation and improves motor recovery. J. Neurotrauma 25, 449-465. doi: 10.1089/neu.2007.0392

Gonzalez-Rothi, E. J., Armstrong, G. T., Cerreta, A. J., Fitzpatrick, G. M., Reier, P. J., Lane, M. A., et al. (2016). Forelimb muscle plasticity following unilateral cervical spinal cord injury: short reports. Muscle Nerve 53, 475-478. doi: 10. 1002/mus.25007

Gonzalez-Rothi, E. J., Rombola, A. M., Rousseau, C. A., Mercier, L. M., Fitzpatrick, G. M., Reier, P. J., et al. (2015). Spinal interneurons and forelimb plasticity after incomplete cervical spinal cord injury in adult rats. J. Neurotrauma 32, 893-907. doi: $10.1089 /$ neu. 2014.3718

Gorgey, A. S., Witt, O., O’Brien, L., Cardozo, C., Chen, Q., Lesnefsky, E. J., et al. (2019). Mitochondrial health and muscle plasticity after spinal cord injury. Eur. J. Appl. Physiol. 119, 315-331. doi: 10.1007/s00421-018-4039-0

Gossard, J.-P., Delivet-Mongrain, H., Martinez, M., Kundu, A., Escalona, M., and Rossignol, S. (2015). Plastic changes in lumbar locomotor networks after a partial spinal cord injury in cats. J. Neurosci. Off. J. Soc. Neurosci. 35, 9446-9455. doi: 10.1523/JNEUROSCI.4502-14.2015

Goto, F., Straka, H., and Dieringer, N. (2002). Gradual and reversible central vestibular reorganization in frog after selective labyrinthine nerve branch lesions. Exp. Brain Res. 147, 374-386. doi: 10.1007/s00221-002-1266-7

Goulding, M. (2009). Circuits controlling vertebrate locomotion: moving in a new direction. Nat. Rev. Neurosci. 10, 507-518. doi: 10.1038/nrn2608

Granier, C., Schwarting, J., Fourli, E., Laage-Gaupp, F., Hennrich, A. A., Schmalz, A., et al. (2020). Formation of somatosensory detour circuits mediates functional recovery following dorsal column injury. Sci. Rep. 10:10953. doi: 10.1038/s41598-020-67866-x

Gransee, H. M., Gonzalez Porras, M. A., Zhan, W.-Z., Sieck, G. C., and Mantilla, C. B. (2017). Motoneuron glutamatergic receptor expression following recovery from cervical spinal hemisection: glutamatergic expression following recovery. J. Comp. Neurol. 525, 1192-1205. doi: 10.1002/cne.24125

Grillner, S., and El Manira, A. (2020). Current principles of motor control, with special reference to vertebrate locomotion. Physiol. Rev. 100, 271-320. doi: 10.1152/physrev.00015.2019

Grillner, S., Hellgren, J., Menard, A., Saitoh, K., and Wikstrom, M. (2005). Mechanisms for selection of basic motor programs - roles for the striatum and pallidum. Trends Neurosci. 28, 364-370. doi: 10.1016/j.tins.2005.05.004

Grillner, S., and Kozlov, A. (2021). The CPGs for limbed locomotion-facts and fiction. Int. J. Mol. Sci. 22:5882. doi: 10.3390/ijms22115882
Grillner, S., Wallén, P., Saitoh, K., Kozlov, A., and Robertson, B. (2008). Neural bases of goal-directed locomotion in vertebrates-an overview. Brain Res. Rev. 57, 2-12. doi: 10.1016/j.brainresrev.2007.06.027

Grodd, W., Hülsmann, E., Lotze, M., Wildgruber, D., and Erb, M. (2001). Sensorimotor mapping of the human cerebellum: fMRI evidence of somatotopic organization: sensorimotor mapping of the cerebellum. Hum. Brain Mapp. 13, 55-73. doi: 10.1002/hbm.1025

Guillaud, E., Faure, C., Doat, E., Bouyer, L. J., Guehl, D., and Cazalets, J.-R. (2020). Ancestral persistence of vestibulo-spinal reflexes in axial muscles in humans. J. Neurophysiol. 123, 2010-2023. doi: 10.1152/jn.00421.2019

Heckman, C. J., Gorassini, M. A., and Bennett, D. J. (2005). Persistent inward currents in motoneuron dendrites: implications for motor output. Muscle Nerve 31, 135-156. doi: 10.1002/mus.20261

Helgren, M. E., and Goldberger, M. E. (1993). The recovery of postural reflexes and locomotion following low thoracic hemisection in adult cats involves compensation by undamaged primary afferent pathways. Exp. Neurol. 123, 17-34. doi: 10.1006/exnr.1993.1137

Holló, G. (2015). A new paradigm for animal symmetry. Interface Focus 5:20150032. doi: 10.1098/rsfs.2015.0032

Hordacre, B., Austin, D., Brown, K. E., Graetz, L., Pareés, I., De Trane, S., et al. (2021). Evidence for a window of enhanced plasticity in the human motor cortex following ischemic stroke. Neurorehabil. Neural Repair 35, 307-320. doi: 10.1177/1545968321992330

Hou, S., Carson, D. M., Wu, D., Klaw, M. C., Houlé, J. D., and Tom, V. J. (2016). Dopamine is produced in the rat spinal cord and regulates micturition reflex after spinal cord injury. Exp. Neurol. 285, 136-146. doi: 10.1016/j.expneurol. 2015.12.001

Hough, R. A., Pale, T., Benes, J. A., and McClellan, A. D. (2021). Spinal cord injury significantly alters the properties of reticulospinal neurons: I. Biophysical properties, firing patterns, excitability, and synaptic inputs. Cells 10:1921. doi: 10.3390/cells 10081921

Hudson, P. E., Corr, S. A., and Wilson, A. M. (2012). High speed galloping in the cheetah (Acinonyx jubatus) and the racing greyhound (Canis familiaris): spatio-temporal and kinetic characteristics. J. Exp. Biol. 215, 2425-2434. doi: 10.1242/jeb.066720

Hurteau, M.-F., and Frigon, A. (2018). A spinal mechanism related to left-right symmetry reduces cutaneous reflex modulation independently of speed during split-belt locomotion. J. Neurosci. 38, 10314-10328. doi: 10.1523/JNEUROSCI. 1082-18.2018

Husch, A., Van Patten, G. N., Hong, D. N., Scaperotti, M. M., Cramer, N., and Harris-Warrick, R. M. (2012). Spinal cord injury induces serotonin supersensitivity without increasing intrinsic excitability of mouse V2a interneurons. J. Neurosci. 32, 13145-13154. doi: 10.1523/JNEUROSCI.2995-12. 2012

Igarashi, M., Alford, B. R., Watanabe, T., and Maxian, P. M. (1969). Role of neck proprioceptors for the maintenance of dynamic bodily equilbrium in the squirrel monkey. Laryngoscope 79, 1713-1727. doi: 10.1288/00005537196910000-00003

Imai, S., Hase, K., Imanaka, K., Suzuki, E., Tanaka, N., and Liu, M. (2005). Motor strategies responsible for maintaining standing posture after deafferentation of the unilateral leg. Arch. Phys. Med. Rehabil. 86, 2027-2033. doi: 10.1016/j.apmr. 2005.04.019

Immisch, I., Quintern, J., and Straube, A. (2003). Unilateral cerebellar lesions influence arm movements bilaterally. Neuroreport 14, 837-840. doi: 10.1097/ 00001756-200305060-00012

Jaarsma, D., Ruigrok, T. J. H., Caffé, R., Cozzari, C., Levey, A. I., Mugnaini, E., et al. (1997). Cholinergic innervation and receptors in the cerebellum. Prog. Brain Res. 114, 67-96. doi: 10.1016/S0079-6123(08)63359-2

Jahn, K., Strupp, M., Schneider, E., Dieterich, M., and Brandt, T. (2000). Differential effects of vestibular stimulation on walking and running. NeuroReport 11, 1745-1748. doi: 10.1097/00001756-200006050-00029

Jamali, M., Mitchell, D. E., Dale, A., Carriot, J., Sadeghi, S. G., and Cullen, K. E. (2014). Neuronal detection thresholds during vestibular compensation: contributions of response variability and sensory substitution: neuronal detection thresholds during vestibular compensation. J. Physiol. 592, 15651580. doi: 10.1113/jphysiol.2013.267534 
Jankelowitz, S. K., Howells, J., and Burke, D. (2007). Plasticity of inwardly rectifying conductances following a corticospinal lesion in human subjects: plasticity of I H. J. Physiol. 581, 927-940. doi: 10.1113/jphysiol.2006.123661

Jay, M., and McLean, D. L. (2021). Locomotor control: inhibiting actions locally and senses globally. Curr. Biol. 31, R1035-R1037. doi: 10.1016/j.cub.2021.07. 050

Jensen, D. W. (1979b). Vestibular compensation: tonic spinal influence upon spontaneous descending vestibular nuclear activity. Neuroscience 4, 1075-1084. doi: 10.1016/0306-4522(79)90188-X

Jensen, D. W. (1979a). Reflex control of acute postural asymmetry and compensatory symmetry after a unilateral vestibular lesion. Neuroscience 4, 1059-1073. doi: 10.1016/0306-4522(79)90187-8

Jiang, Y.-Q., Williams, P. T. J. A., and Martin, J. H. (2013). Rapid and persistent impairments of the forelimb motor representations following cervical deafferentation in rats. Eur. J. Neurosci. 38, 3702-3711. doi: 10.1111/ejn.12372

Johnston, A. R., Seckl, J. R., and Dutia, M. B. (2002). Role of the flocculus in mediating vestibular nucleus neuron plasticity during vestibular compensation in the rat. J. Physiol. 545, 903-911. doi: 10.1113/jphysiol.2002.024281

Juvin, L., Le Gal, J.-P., Simmers, J., and Morin, D. (2012). Cervicolumbar coordination in mammalian quadrupedal locomotion: role of spinal thoracic circuitry and limb sensory inputs. J. Neurosci. Off. J. Soc. Neurosci. 32, 953-965. doi: 10.1523/JNEUROSCI.4640-11.2012

Juvin, L., Simmers, J., and Morin, D. (2005). Propriospinal circuitry underlying interlimb coordination in mammalian quadrupedal locomotion. J. Neurosci. Off. J. Soc. Neurosci. 25, 6025-6035. doi: 10.1523/JNEUROSCI.0696-05.2005

Kaas, J. H., Qi, H.-X., Burish, M. J., Gharbawie, O. A., Onifer, S. M., and Massey, J. M. (2008). Cortical and subcortical plasticity in the brains of humans, primates, and rats after damage to sensory afferents in the dorsal columns of the spinal cord. Exp. Neurol. 209, 407-416. doi: 10.1016/j.expneurol.2007.0 6.014

Kaegi, S., Schwab, M. E., Dietz, V., and Fouad, K. (2001). Electromyographic activity associated with spontaneous functional recovery after spinal cord injury in rats: recovery in spinal cord injured rats. Eur. J. Neurosci. 16, 249-258. doi: 10.1046/j.1460-9568.2002.02076.x

Kasumacic, N., Lambert, F. M., Coulon, P., Bras, H., Vinay, L., Perreault, M.C., et al. (2015). Segmental organization of vestibulospinal inputs to spinal interneurons mediating crossed activation of thoracolumbar motoneurons in the neonatal mouse. J. Neurosci. 35, 8158-8169. doi: 10.1523/JNEUROSCI. 5188-14.2015

Khaing, Z. Z., Geissler, S. A., Jiang, S., Milman, B. D., Aguilar, S. V., Schmidt, C. E., et al. (2012). Assessing forelimb function after unilateral cervical spinal cord injury: novel forelimb tasks predict lesion severity and recovery. J. Neurotrauma 29, 488-498. doi: 10.1089/neu.2011.2106

Kim, B. G., Dai, H.-N., McAtee, M., and Bregman, B. S. (2008). Modulation of dendritic spine remodeling in the motor cortex following spinal cord injury: effects of environmental enrichment and combinatorial treatment with transplants and neurotrophin-3. J. Comp. Neurol. 508, 473-486. doi: 10.1002/ cne. 21686

Kim, B. G., Dai, H.-N., McAtee, M., Vicini, S., and Bregman, B. S. (2006). Remodeling of synaptic structures in the motor cortex following spinal cord injury. Exp. Neurol. 198, 401-415. doi: 10.1016/j.expneurol.2005.12.010

Kitahara, T., Takeda, N., Emson, P. C., Kubo, T., and Kiyama, H. (1997a). Changes in nitric oxide synthase-like immunoreactivities in unipolar brush cells in the rat cerebellar flocculus after unilateral labyrinthectomy. Brain Res. 765, 1-6. doi: 10.1016/S0006-8993(97)00436-8

Kitahara, T., Takedaj, N., Saika, T., Kubo, T., and Kiyama, H. (1997b). Role of the flocculus in the development of vestibular compensation: immunohistochemical studies with retrograde tracing and flocculectomy using Fos expression as a marker in the rat brainstem. Neuroscience 76, 571-580. doi: 10.1016/S0306-4522(96)00374-0

Kitahara, T., Takeda, N., Kubo, T., and Kiyama, H. (1999). Nitric oxide in the flocculus works the inhibitory neural circuits after unilateral labyrinthectomy. Brain Res. 815, 405-409. doi: 10.1016/S0006-8993(98)01113-5

Kitahara, T., Takeda, N., Saika, T., Kubo, T., and Kiyama, H. (1995). Effects of MK801 on Fos expression in the rat brainstem after unilateral labyrinthectomy. Brain Res. 700, 182-190. doi: 10.1016/0006-8993(95)00950-U

Kitahara, T., Takeda, N., Uno, A., Kubo, T., Mishina, M., and Kiyama, H. (1998). Unilateral labyrinthectomy downregulates glutamate receptor d-2 expression in the rat vestibulocerebellum. Mol. Brain Res. 61, 170-178. doi: 10.1016/s0169$328 \mathrm{x}(98) 00228-9$

Knikou, M. (2010). Neural control of locomotion and training-induced plasticity after spinal and cerebral lesions. Clin. Neurophysiol. 121, 1655-1668. doi: 10. 1016/j.clinph.2010.01.039

Knikou, M. (2012). Function of group IB inhibition during assisted stepping in human spinal cord injury. J. Clin. Neurophysiol. 29, 271-277. doi: 10.1097/ WNP.0b013e318257c2b7

Kozlov, A., Huss, M., Lansner, A., Kotaleski, J. H., and Grillner, S. (2009). Simple cellular and network control principles govern complex patterns of motor behavior. Proc. Natl. Acad. Sci. U.S.A. 106, 20027-20032. doi: 10.1073/pnas. 0906722106

Krauss, E. M., and Misiaszek, J. E. (2007). Phase-specific modulation of the soleus $\mathrm{H}$-reflex as a function of threat to stability during walking. Exp. Brain Res. 181, 665-672. doi: 10.1007/s00221-007-0962-8

Kunkel, A. W., and Dieringer, N. (1994). Morphological and electrophysiological consequences of unilateral pre- versus postganglionic vestibular lesions in the frog. J. Comp. Physiol. A 174, 621-632. doi: 10.1007/BF00217383

Kurabe, S., Itoh, K., Matsuzawa, H., Nakada, T., and Fujii, Y. (2014). Expansion of sensorimotor cortical activation for unilateral hand motion during contralateral hand deafferentation. NeuroReport 25, 435-439. doi: 10.1097/ WNR.0000000000000138

Lacour, M., Helmchen, C., and Vidal, P.-P. (2016). Vestibular compensation: the neuro-otologist's best friend. J. Neurol. 263(Suppl. 1), S54-S64. doi: 10.1007/ s00415-015-7903-4

Lacour, M., Roll, J. P., and Appaix, M. (1976). Modifications and development of spinal reflexes in the alert baboon (Papio papio) following an unilateral vestibular neurotomy. Brain Res. 113, 255-269. doi: 10.1016/0006-8993(76) 90940-9

Lacour, M., and Tighilet, B. (2010). Plastic events in the vestibular nuclei during vestibular compensation: the brain orchestration of a "deafferentation" code. Restor. Neurol. Neurosci. 28, 19-35. doi: 10.3233/RNN-2010-0509

Lacour, M., and Xerri, C. (1980). Compensation of postural reactions to free-fall in the vestibular neurectomized monkey: role of the visual motions cues. Exp. Brain Res. 40, 103-110. doi: 10.1007/BF00236668

Lambert, F. M., Beck, J. C., Baker, R., and Straka, H. (2008). Semicircular canal size determines the developmental onset of angular vestibuloocular reflexes in larval Xenopus. J. Neurosci. 28, 8086-8095. doi: 10.1523/JNEUROSCI.1288-08.2008

Lambert, F. M., Malinvaud, D., Gratacap, M., Straka, H., and Vidal, P.-P. (2013). Restricted neural plasticity in vestibulospinal pathways after unilateral labyrinthectomy as the origin for scoliotic deformations. J. Neurosci. 33, 68456856. doi: 10.1523/JNEUROSCI.4842-12.2013

Lambert, F. M., and Straka, H. (2012). The frog vestibular system as a model for lesion-induced plasticity: basic neural principles and implications for posture control. Front. Neurol. 3:42. doi: 10.3389/fneur.2012.00042

Le Ray, D., Juvin, L., Boutin, T., Auclair, F., and Dubuc, R. (2010). A neuronal substrate for a state-dependent modulation of sensory inputs in the brainstem: MLR-induced depression of sensory inputs. Eur. J. Neurosci. 32, 53-59. doi: 10.1111/j.1460-9568.2010.07276.x

Le Ray, D., Juvin, L., Ryczko, D., and Dubuc, R. (2011). Supraspinal control of locomotion. Prog. Brain Res. 188, 51-70. doi: 10.1016/B978-0-444-53825-3. 00009-7

Leiras, R., Cregg, J. M., and Kiehn, O. (2022). Brainstem circuits for locomotion. Annu. Rev. Neurosci. [Epub ahead of print]. doi: 10.1146/annurev-neuro082321-025137

Li, Y., Gorassini, M. A., and Bennett, D. J. (2004). Role of persistent sodium and calcium currents in motoneuron firing and spasticity in chronic spinal rats. J. Neurophysiol. 91, 767-783. doi: 10.1152/jn.00788.2003

Little, J. W., Ditunno, J. F., Stiens, S. A., and Harris, R. M. (1999). Incomplete spinal cord injury: neuronal mechanisms of motor recovery and hyperreflexia. Arch. Phys. Med. Rehabil. 80, 587-599. doi: 10.1016/S0003-9993(99)90204-6

Llinás, R., Walton, K., Hillman, D. E., and Sotelo, C. (1975). Inferior olive: its role in motor learing. Science 190, 1230-1231. doi: 10.1126/science.128123

Loy, D. N., Magnuson, D. S. K., Zhang, Y. P., Onifer, S. M., Mills, M. D., Cao, Q., et al. (2002). Functional redundancy of ventral spinal locomotor pathways. J. Neurosci. 22, 315-323. doi: 10.1523/JNEUROSCI.22-01-00315.2002

Luyten, W. H. M. L., Sharp, F. R., and Ryan, A. F. (1986). Regional differences of brain glucose metabolic compensation after unilateral labyrinthectomy in rats: a 
[14C]2-deoxyglucose study. Brain Res. 373, 68-80. doi: 10.1016/0006-8993(86) 90316-1

MacKinnon, C. D. (2018). Sensorimotor anatomy of gait, balance, and falls. Handb. Clin. Neurol. 159, 3-26. doi: 10.1016/B978-0-444-63916-5.00001-X

Maeda, M. (1988). Mechanisms of vestibular compensation in the unilateral labyrinthectomized cat. Prog. Brain Res. 76, 385-394. doi: 10.1016/S00796123(08)64525-2

Magnusson, A. K., Lindström, S., and Tham, R. (2000). GABA B receptors contribute to vestibular compensation after unilateral labyrinthectomy in pigmented rats. Exp. Brain Res. 134, 32-41. doi: 10.1007/s002210000438

Makin, T. R., and Flor, H. (2020). Brain (re)organisation following amputation: implications for phantom limb pain. NeuroImage 218:116943. doi: 10.1016/j. neuroimage.2020.116943

Mantilla, C. B., Zhan, W.-Z., Gransee, H. M., Prakash, Y. S., and Sieck, G. C. (2018). Phrenic motoneuron structural plasticity across models of diaphragm muscle paralysis. J. Comp. Neurol. 526, 2973-2983. doi: 10.1002/cne.24503

Martinez, M., Brezun, J.-M., Zennou-Azogui, Y., Baril, N., and Xerri, C. (2009). Sensorimotor training promotes functional recovery and somatosensory cortical map reactivation following cervical spinal cord injury: recovery and cortical plasticity after SCI. Eur. J. Neurosci. 30, 2356-2367. doi: 10.1111/j.14609568.2009.07019.x

Martinez, M., Delcour, M., Russier, M., Zennou-Azogui, Y., Xerri, C., Coq, J.-O., et al. (2010). Differential tactile and motor recovery and cortical map alteration after C4-C5 spinal hemisection. Exp. Neurol. 221, 186-197. doi: 10.1016/j. expneurol.2009.10.022

Martinez, M., Delivet-Mongrain, H., and Rossignol, S. (2013). Treadmill training promotes spinal changes leading to locomotor recovery after partial spinal cord injury in cats. J. Neurophysiol. 109, 2909-2922. doi: 10.1152/jn.01044.2012

Mbongo, F., Patko, T., Vidal, P. P., Vibert, N., Tran Ba Huy, P., and de Waele, C. (2005). Postural control in patients with unilateral vestibular lesions is more impaired in the roll than in the pitch plane: a static and dynamic posturography study. Audiol. Neurotol. 10, 291-302. doi: 10.1159/000086081

McCollum, G. (2007). Spatial symmetry groups as sensorimotor guidelines. J. Vestib. Res. 17, 347-359. doi: 10.3233/ves-2007-175-614

Merlet, A. N., Harnie, J., and Frigon, A. (2021). Inhibition and facilitation of the spinal locomotor central pattern generator and reflex circuits by somatosensory feedback from the lumbar and perineal regions after spinal cord injury. Front. Neurosci. 15:720542. doi: 10.3389/fnins.2021.720542

Minatohara, K., Akiyoshi, M., and Okuno, H. (2016). Role of immediate-early genes in synaptic plasticity and neuronal ensembles underlying the memory trace. Front. Mol. Neurosci. 8:78. doi: 10.3389/fnmol.2015.00078

Montardy, Q., Wei, M., Liu, X., Yi, T., Zhou, Z., Lai, J., et al. (2021). Selective optogenetic stimulation of glutamatergic, but not GABAergic, vestibular nuclei neurons induces immediate and reversible postural imbalance in mice. Prog. Neurobiol. 204:102085. doi: 10.1016/j.pneurobio.2021.102085

Moubayidin, L., and Østergaard, L. (2015). Symmetry matters. New Phytol. 207, 985-990. doi: 10.1111/nph.13526

Mu, Y., Bennett, D. V., Rubinov, M., Narayan, S., Yang, C.-T., Tanimoto, M., et al. (2019). Glia accumulate evidence that actions are futile and suppress unsuccessful behavior. Cell 178, 27.e19-43.e19. doi: 10.1016/j.cell.2019.05.050

Muir, G. D., Katz, S. L., Gosline, J. M., and Steeves, J. D. (1998). Asymmetric bipedal locomotion - an adaptive response to incomplete spinal injury in the chick. Exp. Brain Res. 122, 275-282. doi: 10.1007/s002210050515

Muir, G. D., and Steeves, J. D. (1995). Phasic cutaneous input facilitates locomotor recovery after incomplete spinal injury in the chick. J. Neurophysiol. 74, 358368. doi: 10.1152/jn.1995.74.1.358

Musienko, P. E., Deliagina, T. G., Gerasimenko, Y. P., Orlovsky, G. N., and Zelenin, P. V. (2014). Limb and trunk mechanisms for balance control during locomotion in quadrupeds. J. Neurosci. 34, 5704-5716. doi: 10.1523/ JNEUROSCI.4663-13.2014

Nardone, R., Höller, Y., Brigo, F., Seidl, M., Christova, M., Bergmann, J., et al. (2013). Functional brain reorganization after spinal cord injury: systematic review of animal and human studies. Brain Res. 1504, 58-73. doi: 10.1016/j. brainres.2012.12.034

Newlands, S. D., and Perachio, A. A. (1990). Compensation of horizontal canal related activity in the medial vestibular nucleus following unilateral labyrinth ablation in the decerebrate gerbil. Exp. Brain Res. 82, 359-372. doi: 10.1007/ bf00231255
Nielson, J. L., Sears-Kraxberger, I., Strong, M. K., Wong, J. K., Willenberg, R., and Steward, O. (2010). Unexpected survival of neurons of origin of the pyramidal tract after spinal cord injury. J. Neurosci. 30, 11516-11528. doi: 10.1523/JNEUROSCI.1433-10.2010

Noorimotlagh, Z., Babaie, M., Safdarian, M., Ghadiri, T., and Rahimi-Movaghar, V. (2017). Mechanisms of spinal cord injury regeneration in zebrafish: a systematic review. Iran. J. Basic Med. Sci. 20, 1287-1296. doi: 10.22038/ijbms.2017.9620

Okada, S., Hara, M., Kobayakawa, K., Matsumoto, Y., and Nakashima, Y. (2018). Astrocyte reactivity and astrogliosis after spinal cord injury. Neurosci. Res. 126, 39-43. doi: 10.1016/j.neures.2017.10.004

Olabi, B., Bergquist, F., and Dutia, M. B. (2009). Rebalancing the commissural system: mechanisms of vestibular compensation. J. Vestib. Res. 19, 201-207. doi: 10.3233/VES-2009-0367

Olechowski-Bessaguet, A., Grandemange, R., Cardoit, L., Courty, E., Lambert, F. M., and Le Ray, D. (2020). Functional organization of vestibulospinal inputs on thoracic motoneurons responsible for trunk postural control in Xenopus. J. Physiol. 598, 817-838. doi: 10.1113/JP278599

Olivares-Moreno, R., Rodriguez-Moreno, P., Lopez-Virgen, V., Macías, M., Altamira-Camacho, M., and Rojas-Piloni, G. (2021). Corticospinal vs rubrospinal revisited: an evolutionary perspective for sensorimotor integration. Front. Neurosci. 15:686481. doi: 10.3389/fnins.2021.686481

Overduin, S. A., and Servos, P. (2008). Symmetric sensorimotor somatotopy. PLoS One 3:e1505. doi: 10.1371/journal.pone.0001505

Paterson, J. M., Short, D., Flatman, P. W., Seckl, J. R., Aitken, A., and Dutia, M. B. (2006). Changes in protein expression in the rat medial vestibular nuclei during vestibular compensation: proteomics of vestibular compensation. J. Physiol. 575, 777-788. doi: 10.1113/jphysiol.2006.112409

Patrickson, J. W., Bryant, H. J., Kaderkaro, M., and Kutyna, F. A. (1985). A quantitative [14C]-2-deoxy-D-glucose study of brain stem nuclei during horizontal nystagmus induced by lesioning the lateral crista ampullaris of the rat. Exp. Brain Res. 60, 227-234. doi: 10.1007/BF00235917

Pavlova, E. L., Popova, L. B., Orlovsky, G. N., and Deliagina, T. G. (2004). Vestibular compensation in lampreys: restoration of symmetry in reticulospinal commands. J. Exp. Biol. 207, 4595-4603. doi: 10.1242/jeb.6247

Perez, M. A., Field-Fote, E. C., and Floeter, M. K. (2003). Patterned sensory stimulation induces plasticity in reciprocal Ia inhibition in humans. J. Neurosci. 23, 2014-2018. doi: 10.1523/JNEUROSCI.23-06-02014.2003

Perrier, J.-F., Rasmussen, H., Christensen, R., and Petersen, A. (2013). Modulation of the intrinsic properties of motoneurons by serotonin. Curr. Pharm. Des. 19, 4371-4384. doi: 10.2174/13816128113199990341

Peterka, R. J., Statler, K. D., Wrisley, D. M., and Horak, F. B. (2011). Postural compensation for unilateral vestibular loss. Front. Neurol. 2:57. doi: 10.3389/ fneur.2011.00057

Petrosyan, H., Liang, L., Tesfa, A., Sisto, S. A., Fahmy, M., and Arvanian, V. L. (2020). Modulation of H-reflex responses and frequency-dependent depression by repetitive spinal electromagnetic stimulation: from rats to humans and back to chronic spinal cord injured rats. Eur. J. Neurosci. 52, 4875-4889. doi: 10.1111/ ejn. 14885

Pflieger, J.-F., and Dubuc, R. (2004). Vestibulo-reticular projections in adult lamprey: their role in locomotion. Neuroscience 129, 817-829. doi: 10.1016/j. neuroscience.2004.08.025

Phadke, C. P., Flynn, S. M., Thompson, F. J., Behrman, A. L., Trimble, M. H., and Kukulka, C. G. (2009). Comparison of single bout effects of bicycle training versus locomotor training on paired reflex depression of the soleus H-reflex after motor incomplete spinal cord injury. Arch. Phys. Med. Rehabil. 90, 1218-1228. doi: 10.1016/j.apmr.2009.01.022

Pisu, M. B., Conforti, E., Botta, L., Valli, P., and Bernocchi, G. (2002). Nitric oxide synthase in the frog cerebellum: response of Purkinje neurons to unilateral eighth nerve transection. Anat. Rec. 268, 73-83. doi: 10.1002/ar.10138

Power, J. D., and Schlaggar, B. L. (2017). Neural plasticity across the lifespan: neural plasticity across the lifespan. Wiley Interdiscip. Rev. Dev. Biol. 6:e216. doi: 10.1002/wdev.216

Precht, W., Shimazu, H., and Markham, C. H. (1966). A mechanism of central compensation of vestibular function following hemilabyrinthectomy. J. Neurophysiol. 29, 996-1010. doi: 10.1152/jn.1966.29.6.996

Putkonen, P. T. S., Courjon, J. H., and Jeannerod, M. (1977). Compensation of postural effects of hemilabyrinthectomy in the cat. A sensory substitution process? Exp. Brain Res. 28, 249-257. doi: 10.1007/BF00235707 
Raffin, E. (2021). The various forms of sensorimotor plasticity following limb amputation and their link with rehabilitation strategies. Rev. Neurol. 177, 1112-1120. doi: 10.1016/j.neurol.2021.09.003

Rancic, V., and Gosgnach, S. (2021). Recent insights into the rhythmogenic core of the locomotor CPG. Int. J. Mol. Sci. 22:1394. doi: 10.3390/ijms22031394

Rangasamy, S. B. (2013). Locomotor recovery after spinal cord hemisection/contusion injures in bonnet monkeys: footprint testing-a minireview: analysis of footprint variables in monkeys. Synapse 67, 427-453. doi: $10.1002 /$ syn. 21645

Rasmussen, J. P., and Sagasti, A. (2017). Learning to swim, again: axon regeneration in fish. Exp. Neurol. 287, 318-330. doi: 10.1016/j.expneurol.2016.02.022

Rastoldo, G., Marouane, E., El Mahmoudi, N., Péricat, D., Bourdet, A., TimonDavid, E., et al. (2020). Quantitative evaluation of a new posturo-locomotor phenotype in a rodent model of acute unilateral vestibulopathy. Front. Neurol. 11:505. doi: 10.3389/fneur.2020.00505

Raymond, J., Ez-Zaher, L., Demêmes, D., and Lacour, M. (1991). Quantification of synaptic density changes in the medial vestibular nucleus of the cat following vestibular neurectomy. Restor. Neurol. Neurosci. 3, 197-203. doi: 10.3233/RNN1991-3404

Rickmann, M., Wolff, J. R., and Meyer, D. L. (1995). Expression of S100 protein in the vestibular nuclei during compensation of unilateral labyrinthectomy symptoms. Brain Res. 688, 8-14. doi: 10.1016/0006-8993(95)00495-c

Ris, L., Capron, B., de Waele, C., Vidal, P. P., and Godaux, E. (1997). Dissociations between behavioural recovery and restoration of vestibular activity in the unilabyrinthectomized guinea-pig. J. Physiol. 500, 509-522. doi: 10.1113/ jphysiol.1997.sp022037

Ris, L., de Waele, C., Serafin, M., Vidal, P. P., and Godaux, E. (1995). Neuronal activity in the ipsilateral vestibular nucleus following unilateral labyrinthectomy in the alert guinea pig. J. Neurophysiol. 74, 2087-2099. doi: 10.1152/jn.1995.74. 5.2087

Ris, L., and Godaux, E. (1998). Neuronal activity in the vestibular nuclei after contralateral or bilateral labyrinthectomy in the alert guinea pig. J. Neurophysiol. 80, 2352-2367. doi: 10.1152/jn.1998.80.5.2352

Ris, L., Wattiez, R., de Waele, C., Vidal, P.-P., and Godaux, E. (1998). Reappearance of activity in the vestibular neurones of labyrinthectomized guinea-pigs is not delayed by cycloheximide. J. Physiol. 512, 533-541. doi: 10.1111/j.1469-7793. 1998.533be.x

Roberts, A., Li, W.-C., and Soffe, S. R. (2010). How neurons generate behaviour in a hatchling amphibian tadpole: an outline. Front. Behav. Neurosci. 4:16. doi: 10.3389/fnbeh.2010.00016

Robinson, R. (1979). Differential behavioral and biochemical effects of right and left hemispheric cerebral infarction in the rat. Science 205, 707-710. doi: 10.1126/ science. 462179

Romano, F., Bockisch, C. J., Schuknecht, B., Bertolini, G., and Tarnutzer, A. A. (2020). Asymmetry in gaze-holding impairment in acute unilateral ischemic cerebellar lesions critically depends on the involvement of the caudal vermis and the dentate nucleus. Cerebellum 20, 768-779. doi: 10.1007/s12311-020-01141-7

Rossignol, S. (2006). Plasticity of connections underlying locomotor recovery after central and/or peripheral lesions in the adult mammals. Philos. Trans. R. Soc. B Biol. Sci. 361, 1647-1671. doi: 10.1098/rstb.2006.1889

Rossignol, S., Bouyer, L., Barthélemy, D., Langlet, C., and Leblond, H. (2002). Recovery of locomotion in the cat following spinal cord lesions. Brain Res. Rev. 40, 257-266. doi: 10.1016/S0165-0173(02)00208-4

Rossignol, S., Chau, C., Brustein, E., Bélanger, M., Barbeau, H., and Drew, T. (1996). Locomotor capacities after complete and partial lesions of the spinal cord. Acta Neurobiol. Exp. 56, 449-463.

Sadeghi, S. G., Minor, L. B., and Cullen, K. E. (2011). Multimodal integration after unilateral labyrinthine lesion: single vestibular nuclei neuron responses and implications for postural compensation. J. Neurophysiol. 105, 661-673. doi: 10.1152/jn.00788.2010

Sadlaoud, K., Khalki, L., Brocard, F., Vinay, L., Boulenguez, P., and Bras, H. (2020). Alteration of glycinergic receptor expression in lumbar spinal motoneurons is involved in the mechanisms underlying spasticity after spinal cord injury. J. Chem. Neuroanat. 106:101787. doi: 10.1016/j.jchemneu.2020.101787

Sadlaoud, K., Tazerart, S., Brocard, C., Jean-Xavier, C., Portalier, P., Brocard, F., et al. (2010). Differential plasticity of the GABAergic and glycinergic synaptic transmission to rat lumbar motoneurons after spinal cord injury. J. Neurosci. 30, 3358-3369. doi: 10.1523/JNEUROSCI.6310-09.2010
Sans, N., Sans, A., and Raymond, J. (1997). Regulation of NMDA receptor subunit mRNA expression in the guinea pig vestibular nuclei following unilateral labyrinthectomy. Eur. J. Neurosci. 9, 2019-2034. doi: 10.1111/j.1460-9568.1997. tb01370.x

Saunders, J. B., Inman, V. T., and Eberhart, H. D. (1953). The major determinants in normal and pathological gait. J. Bone Joint Surg. Am. 35, 543-558. doi: 10.2106/00004623-195335030-00003

Schaefer, K.-P., and Meyer, D. L. (1973). "Compensatory mechanisms following labyrinthine lesions in the guinea-pig. a simple model of learning," in Memory and Transfer of Information: Proceedings of a symposium sponsored by the Merck'sche Gesellschaft für Kunst und Wissenschaft (Göttingen, May 24-26, 1972), ed. H. P. Zippel (Boston, MA: Springer US), 203-232. doi: 10.1007/9781-4684-2052-4_9

Schaefer, K.-P., Meyer, D. L., and Wilhelms, G. (1979). Somatosensory and cerebellar influences on compensation of labyrinthine lesions. Prog. Brain Res. 50, 591-598. doi: 10.1016/S0079-6123(08)60857-2

Schniepp, R., Möhwald, K., and Wuehr, M. (2017). Gait ataxia in humans: vestibular and cerebellar control of dynamic stability. J. Neurol. 264, 87-92. doi: 10.1007/s00415-017-8482-3

Schniepp, R., Wuehr, M., Neuhaeusser, M., Kamenova, M., Dimitriadis, K., Klopstock, T., et al. (2012). Locomotion speed determines gait variability in cerebellar ataxia and vestibular failure. Mov. Disord. 27, 125-131. doi: 10.1002/ mds. 23978

Schucht, P., Raineteau, O., Schwab, M. E., and Fouad, K. (2002). Anatomical correlates of locomotor recovery following dorsal and ventral lesions of the rat spinal cord. Exp. Neurol. 176, 143-153. doi: 10.1006/exnr.2002. 7909

Schuknecht, H. F. (1982). Behavior of the vestibular nerve following labyrinthectomy. Ann. Otol. Rhinol. Laryngol. Suppl. 97, 16-32.

Schulte, J. T., Wierenga, C. J., and Bruining, H. (2018). Chloride transporters and GABA polarity in developmental, neurological and psychiatric conditions. Neurosci. Biobehav. Rev. 90, 260-271. doi: 10.1016/j.neubiorev.2018.05. 001

Schweickert, A., Ott, T., Kurz, S., Tingler, M., Maerker, M., Fuhl, F., et al. (2018). Vertebrate left-right asymmetry: what can nodal cascade gene expression patterns tell us? J. Cardiovasc. Dev. Dis. 5, 1-12. doi: 10.3390/jcdd5010001

Scivoletto, G., Ivanenko, Y., Morganti, B., Grasso, R., Zago, M., Lacquaniti, F., et al. (2007). Plasticity of spinal centers in spinal cord injury patients: new concepts for gait evaluation and training. Neurorehabil. Neural Repair 21, 358-365. doi: $10.1177 / 1545968306295561$

Shiller, D. M., Veilleux, L.-N., Marois, M., Ballaz, L., and Lemay, M. (2017). Sensorimotor adaptation of whole-body postural control. Neuroscience 356, 217-228. doi: 10.1016/j.neuroscience.2017.05.029

Simon, F., Pericat, D., Djian, C., Fricker, D., Denoyelle, F., and Beraneck, M. (2020). Surgical techniques and functional evaluation for vestibular lesions in the mouse: unilateral labyrinthectomy (UL) and unilateral vestibular neurectomy (UVN). J. Neurol. 267, 51-61. doi: 10.1007/s00415-020-09960-8

Singh, A., Balasubramanian, S., Murray, M., Lemay, M., and Houle, J. (2011). Role of spared pathways in locomotor recovery after body-weight-supported treadmill training in contused rats. J. Neurotrauma 28, 2405-2416. doi: 10.1089/ neu. 2010.1660

Smith, H. L. H., and Galiana, H. L. (1991). The role of structural symmetry in linearizing ocular reflexes. Biol. Cybern. 65, 11-22. doi: 10.1007/BF00197285

Smith, P. F. (2020). Why the cerebellar shutdown/clampdown hypothesis of vestibular compensation is inconsistent with neurophysiological evidence. J. Vestib. Res. 30:10. doi: 10.3233/VES-200715

Spinazzola, L., Cubelli, R., and Della Sala, S. (2003). Impairments of trunk movements following left or right hemisphere lesions: dissociation between apraxic errors and postural instability. Brain 126, 2656-2666. doi: 10.1093/ brain/awg266

Starkey, M. L., Bleul, C., Zörner, B., Lindau, N. T., Mueggler, T., Rudin, M., et al. (2012). Back seat driving: hindlimb corticospinal neurons assume forelimb control following ischaemic stroke. Brain 135, 3265-3281. doi: 10.1093/brain/ aws 270

Stecina, K., and Jankowska, E. (2007). Uncrossed actions of feline corticospinal tract neurones on hindlimb motoneurones evoked via ipsilaterally descending pathways: uncrossed corticospinal actions. J. Physiol. 580, 119-132. doi: 10. 1113/jphysiol.2006.122721 
Stecina, K., Slawinska, U., and Jankowska, E. (2008). Ipsilateral actions from the feline red nucleus on hindlimb motoneurones: ipsilateral rubral actions. J. Physiol. 586, 5865-5884. doi: 10.1113/jphysiol.2008.163998

Straka, H., and Baker, R. (2013). Vestibular blueprint in early vertebrates. Front. Neural Circ. 7:182. doi: 10.3389/fncir.2013.00182

Straka, H., and Dieringer, N. (1995). Spinal plasticity after hemilabyrinthectomy and its relation to postural recovery in the frog. J. Neurophysiol. 73, 1617-1631. doi: 10.1152/jn.1995.73.4.1617

Straka, H., and Dieringer, N. (2004). Basic organization principles of the VOR: lessons from frogs. Prog. Neurobiol. 73, 259-309. doi: 10.1016/j.pneurobio. 2004. 05.003

Straka, H., Simmers, J., and Chagnaud, B. P. (2018). A new perspective on predictive motor signaling. Curr. Biol. 28, R232-R243. doi: 10.1016/j.cub.2018. 01.033

Streeter, K. A., Sunshine, M. D., Patel, S. R., Gonzalez-Rothi, E. J., Reier, P. J., Baekey, D. M., et al. (2020). Mid-cervical interneuron networks following high cervical spinal cord injury. Respir. Physiol. Neurobiol. 271:103305. doi: 10.1016/ j.resp.2019.103305

Takahashi, M., and Shinoda, Y. (2021). Neural circuits of inputs and outputs of the cerebellar cortex and nuclei. Neuroscience 462, 70-88. doi: 10.1016/j. neuroscience.2020.07.051

Takakusaki, K. (2017). Functional neuroanatomy for posture and gait control. J. Mov. Disord. 10, 1-17. doi: 10.14802/jmd.16062

Takakusaki, K., Chiba, R., Nozu, T., and Okumura, T. (2016). Brainstem control of locomotion and muscle tone with special reference to the role of the mesopontine tegmentum and medullary reticulospinal systems. J. Neural Transm. 123, 695-729. doi: 10.1007/s00702-015-1475-4

Takatsuru, Y., Fukumoto, D., Yoshitomo, M., Nemoto, T., Tsukada, H., and Nabekura, J. (2009). Neuronal circuit remodeling in the contralateral cortical hemisphere during functional recovery from cerebral infarction. J. Neurosci. 29, 10081-10086. doi: 10.1523/JNEUROSCI.1638-09.2009

Takeoka, A., Vollenweider, I., Courtine, G., and Arber, S. (2014). Muscle spindle feedback directs locomotor recovery and circuit reorganization after spinal cord injury. Cell 159, 1626-1639. doi: 10.1016/j.cell.2014.11.019

Tan, A. M., Chakrabarty, S., Kimura, H., and Martin, J. H. (2012). Selective corticospinal tract injury in the rat induces primary afferent fiber sprouting in the spinal cord and hyperreflexia. J. Neurosci. 32, 12896-12908. doi: 10.1523/ JNEUROSCI.6451-11.2012

Tazerart, S., Viemari, J.-C., Darbon, P., Vinay, L., and Brocard, F. (2007). Contribution of persistent sodium current to locomotor pattern generation in neonatal rats. J. Neurophysiol. 98:16. doi: 10.1152/jn.00316.2007

Tazerart, S., Vinay, L., and Brocard, F. (2008). The persistent sodium current generates pacemaker activities in the central pattern generator for locomotion and regulates the locomotor rhythm. J. Neurosci. 28, 8577-8589. doi: 10.1523/ JNEUROSCI.1437-08.2008

Thompson, A. K., and Wolpaw, J. R. (2015). Restoring walking after spinal cord injury: operant conditioning of spinal reflexes can help. Neuroscientist 21, 203-215. doi: 10.1177/1073858414527541

Thoumie, P., and Do, M. C. (1996). Changes in motor activity and biomechanics during balance recovery following cutaneous and muscular deafferentation. Exp. Brain Res. 110, 289-297. doi: 10.1007/BF00228559

Tighilet, B., Brezun, J. M., Dit Duflo Sylvie, G., Gaubert, C., and Lacour, M. (2007). New neurons in the vestibular nuclei complex after unilateral vestibular neurectomy in the adult cat: reactive neurogenesis in adult vestibular lesioned cats. Eur. J. Neurosci. 25, 47-58. doi: 10.1111/j.1460-9568.2006.05267.x

Tighilet, B., and Chabbert, C. (2019). Adult neurogenesis promotes balance recovery after vestibular loss. Prog. Neurobiol. 174, 28-35. doi: 10.1016/j. pneurobio.2019.01.001

Tighilet, B., and Lacour, M. (1998). Distribution of choline acetyltransferase immunoreactivity in the vestibular nuclei of normal and unilateral vestibular neurectomized cats: ChAT-Ir changes in vestibular lesioned cats. Eur. J. Neurosci. 10, 3115-3126. doi: 10.1046/j.1460-9568.1998. 00331.x

Tighilet, B., Leonard, J., Mourre, C., and Chabbert, C. (2019). Apamin treatment accelerates equilibrium recovery and gaze stabilization in unilateral vestibular neurectomized cats: cellular and behavioral aspects. Neuropharmacology 144, 133-142. doi: 10.1016/j.neuropharm.2018.10.029
Tighilet, B., Trottier, S., Mourre, C., and Lacour, M. (2006). Changes in the histaminergic system during vestibular compensation in the cat: histamine and vestibular compensation. J. Physiol. 573, 723-739. doi: 10.1113/jphysiol.2006. 107805

Tjernström, F., Fransson, P.-A., Kahlon, B., Karlberg, M., Lindberg, S., Siesjö, P., et al. (2019). Different visual weighting due to fast or slow vestibular deafferentation: before and after schwannoma surgery. Neural Plast. 2019:12. doi: 10.1155/2019/4826238

Torres-Espín, A., Beaudry, E., Fenrich, K., and Fouad, K. (2018). Rehabilitative training in animal models of spinal cord injury. J. Neurotrauma 35, 1970-1985. doi: 10.1089/neu.2018.5906

Vejsada, R., Hník, P., Navarrete, R., Palecek, J., Soukup, T., Borecka, U., et al. (1991). Motor functions in rat hindlimb muscles following neonatal sciatic nerve crush. Neuroscience 40, 267-275. doi: 10.1016/0306-4522(91)90 189-U

Vibert, N., Babalian, A., Serafin, M., Gasc, J.-P., Mühlethaler, M., and Vidal, P.-P. (1999a). Plastic changes underlying vestibular compensation in the guinea-pig persist in isolated, in vitro whole brain preparations. Neuroscience 93, 413-432. doi: 10.1016/S0306-4522(99)00172-4

Vibert, N., Bantikyan, A., Babalian, A., Serafin, M., Mühlethaler, M., and Vidal, P.-P. (1999b). Post-lesional plasticity in the central nervous system of the guinea-pig: a "top-down" adaptation process? Neuroscience 94, 1-5. doi: 10.1016/S0306-4522(99)00323-1

Vibert, N., Beraneck, M., Bantikyan, A., and Vidal, P. P. (2000). Vestibular compensation modifies the sensitivity of vestibular neurones to inhibitory amino acids. Neuroreport 11, 1921-1927. doi: 10.1097/00001756-20000626000023

Vidal, P. P., de Waele, C., Vibert, N., and Mühlethaler, M. (1998). Vestibular compensation revisited. Otolaryngol. Head Neck Surg. Off. J. Am. Acad. Otolaryngol. Head Neck Surg. 119, 34-42. doi: 10.1016/S0194-5998(98)70171-8

Vidal, P. P., Wang, D. H., Graf, W., and de Waele, C. (1993). Vestibular control of skeletal geometry in the guinea pig: a problem of good trim? Prog. Brain Res. 979, 229-243.

von Uckermann, G., Le Ray, D., Combes, D., Straka, H., and Simmers, J. (2013). Spinal efference copy signaling and gaze stabilization during locomotion in juvenile Xenopus frogs. J. Neurosci. 33, 4253-4264. doi: 10.1523/JNEUROSCI. 4521-12.2013

Walz, W. (2000). Role of astrocytes in the clearance of excess extracellular potassium. Neurochem. Int. 36, 291-300. doi: 10.1016/S0197-0186(99)00 137-0

Webb, A. A., and Muir, G. D. (2003). Unilateral dorsal column and rubrospinal tract injuries affect overground locomotion in the unrestrained rat. Eur. J. Neurosci. 18, 412-422. doi: 10.1046/j.1460-9568.2003.02 768.x

White, L., Andrews, T., Hulette, C., Richards, A., Groelle, M., Paydarfar, J., et al. (1997). Structure of the human sensorimotor system. II: lateral symmetry. Cereb. Cortex 7, 31-47. doi: 10.1093/cercor/7.1.31

Wijesinghe, R., and Camp, A. (2020). The intrinsic plasticity of medial vestibular nucleus neurons during vestibular compensation-a systematic review and meta-analysis. Syst. Rev. 9:145. doi: 10.1186/s13643-020-01399-2

Wilmut, K., Gentle, J., and Barnett, A. L. (2017). Gait symmetry in individuals with and without developmental coordination disorder. Res. Dev. Disabil. 60, 107-114. doi: 10.1016/j.ridd.2016.11.016

Wolpaw, J. R., and Lee, C. L. (1989). Memory traces in primate spinal cord produced by operant conditioning of H-reflex. J. Neurophysiol. 61, 563-572. doi: 10.1152/jn.1989.61.3.563

Wu, X., Nestrasil, I., Ashe, J., Tuite, P., and Bushara, K. (2010). Inferior olive response to passive tactile and visual stimulation with variable interstimulus intervals. Cerebellum 9, 598-602. doi: 10.1007/s12311-010-0203-8

Yamanaka, T., Him, A., Cameron, S. A., and Dutia, M. B. (2000). Rapid compensatory changes in GABA receptor efficacy in rat vestibular neurones after unilateral labyrinthectomy. J. Physiol. 523, 413-424. doi: 10.1111/j.14697793.2000.t01-1-00413.x

Zennou-Azogui, Y., Xerri, C., Leonard, J., and Tighilet, B. (1996). Vestibular compensation: role of visual motion cues in the recovery of posturo-kinetic functions in the cat. Behav. Brain Res. 74, 65-77. doi: 10.1016/0166-4328(95) 00142-5 
Zhang, M., Watanabe, H., Sarkisyan, D., Andersen, M. S., Nosova, O., Galatenko, V., et al. (2020). Hindlimb motor responses to unilateral brain injury: spinal cord encoding and left-right asymmetry. Brain Commun. 2:fcaa055. doi: 10. 1093/braincomms/fcaa055

Zörner, B., Bachmann, L. C., Filli, L., Kapitza, S., Gullo, M., Bolliger, M., et al. (2014). Chasing central nervous system plasticity: the brainstem's contribution to locomotor recovery in rats with spinal cord injury. Brain 137, 1716-1732. doi: 10.1093/brain/awu078

Conflict of Interest: The authors declare that the research was conducted in the absence of any commercial or financial relationships that could be construed as a potential conflict of interest.
Publisher's Note: All claims expressed in this article are solely those of the authors and do not necessarily represent those of their affiliated organizations, or those of the publisher, the editors and the reviewers. Any product that may be evaluated in this article, or claim that may be made by its manufacturer, is not guaranteed or endorsed by the publisher.

Copyright $\odot 2022$ Le Ray and Guayasamin. This is an open-access article distributed under the terms of the Creative Commons Attribution License (CC BY). The use, distribution or reproduction in other forums is permitted, provided the original author(s) and the copyright owner(s) are credited and that the original publication in this journal is cited, in accordance with accepted academic practice. No use, distribution or reproduction is permitted which does not comply with these terms. 